\title{
Experimental Determination of Temperature-Dependent Thermal Conductivity of Solid Eicosane-Based Silver Nanostructure-Enhanced Phase Change Materials for Thermal Energy Storage
}

\author{
Rabih M. Al Ghossein ${ }^{\mathrm{a}+}$, Mohammad Sharif Hossain ${ }^{\mathrm{b}+}$ and J. M. Khodadadiax
}

a 1418 Wiggins Hall, Department of Mechanical Engineering, Auburn University, AL 368495341, USA

b 179 Chemistry Building, Department of Chemistry and Biochemistry, Auburn University, AL 36849-5312, USA

\begin{abstract}
Thermal conductivity of eicosane-based phase change materials was enhanced by suspending highly-conductive silver nanoparticles. Three batches of solid eicosane-silver samples with mass fractions $(0,1,2,3.5,5,6.5,8$ and $10 \mathrm{wt} \%)$ of nanoparticles were obtained under three different solidification routes: ice-water bath, room temperature and oven solidification. The transient plane source technique was used to measure the thermal conductivity at different temperatures starting at $10{ }^{\circ} \mathrm{C}$ and ending close to the melting point of each sample. Results showed an increase in the value of thermal conductivity as the temperature increased, and when close to melting point, a sharp rise in thermal conductivity was observed. Also, the oven solidification route samples exhibited the highest values while the ice-water samples showed the least increase. For samples with an additive loading greater than $2 \mathrm{wt} \%$, a non-monotonic relationship was obtained between the thermal conductivity and the weight fraction of Ag nanoparticles,

+ Graduate Research Assistant.

${ }^{\mathrm{x}}$ Corresponding Author; Alumni Chair Professor; Tel: 1(334) 844-3333; Fax: 1(334) 844-3307; khodajm@auburn.edu.
\end{abstract}


regardless of the method of solidification. In addition to thermal conductivity measurement, the latent heat of fusion of the samples was investigated, utilizing differential scanning calorimetry. Results exhibited a decrease in the latent heat and the melting point of the samples as the additives loading increased due to the decrease in the number of molecules of eicosane in the samples.

\section{KEY WORDS}

Differential Scanning Calorimetry; Eicosane; Latent Heat; Phase Change Materials; Silver Nanoparticles; Thermal Conductivity Enhancement; Transient Plane Source Method.

\section{Disclaimer}

This report was prepared as an account of work sponsored by an agency of the United States Government. Neither the United States Government nor any agency thereof, nor any of their employees, makes any warranty, express or implied, or assumes any legal liability or responsibility for the accuracy, completeness, or usefulness of any information, apparatus, product, or process disclosed, or represents that its use would not infringe privately owned rights. References herein to any specific commercial product, process, or service by trade name, trademark, manufacturer, or otherwise do not necessarily constitute or imply its endorsement, recommendation, or favoring by the United States Government or any agency thereof. The views and opinions of authors expressed herein do not necessarily state or reflect those of the United States Government or any agency thereof. 
$\underline{\text { Nomenclature }}$

$\begin{array}{clc}\text { Symbol } & \text { Quantity } & \text { SI Unit } \\ C_{p} & \text { Specific Heat Capacity } & \mathrm{kJ} / \mathrm{kgK} \\ k & \text { Thermal Conductivity } & \mathrm{W} / \mathrm{mK} \\ K_{f} & \text { Molal Freezing-Point-Depression Constant } & \mathrm{kgK} / \mathrm{mol} \\ m & \text { Molality } & \mathrm{mol} / \mathrm{kg} \\ n & \text { Number of Moles } & \mathrm{moles} \\ r & \text { Radius of Sensor } & \mathrm{m} \\ R & \text { Ideal Gas Constant } & \mathrm{J} / \mathrm{molK} \\ R_{t h} & \text { Thermal Resistance } & \mathrm{mK} / \mathrm{W} \\ T & \text { Temperature } & { }^{\circ} \mathrm{C} \text { or K }\end{array}$

\section{Greek Symbols}

$\begin{array}{clc}\alpha & \text { Thermal Diffusivity } & \mathrm{m}^{2} / \mathrm{s} \\ \Delta H & \text { Latent Heat of Fusion } & \mathrm{kJ} / \mathrm{kg} \\ \emptyset_{\mathrm{vol}} & \text { Volume Fraction } & \\ \emptyset_{w t} & \text { Mass Fraction } & \\ \rho & \text { Density } & \mathrm{kg} / \mathrm{m}^{3}\end{array}$




\section{Subscripts}

$\begin{array}{ll}c & \text { Continuous Phase } \\ d & \text { Discrete Phase } \\ \text { eff } & \text { Effective } \\ m & \text { Melting } \\ \text { vol } & \text { Volume } \\ w t & \text { Weight }\end{array}$

\section{Superscripts}

o Pure Sample 


\section{Introduction}

Due to the ongoing growth of economies and greater industrial productivity, more ways to produce energy are needed in order to meet the ever-increasing demand. Fossil fuels have long been the primary source of energy, but due to the hazardous consequences on the environment and the ever-increasing and unstable price of fossil fuels, greater emphasis has been focused on a wider utilization of renewable sources of energy. Solar, wave and wind energies are the most common forms of renewable sources of energy and are known to be clean and sustainable. However, availability of these energy sources is deemed unreliable on many occasions. In effect, the major bottleneck associated with greater implementation of renewable sources of energy has been the issue of its availability during the peak demand periods.

Among the different forms of energy, thermal energy is widely encountered as solar irradiance, geothermal energy, waste heat and thermally stratified layers in oceans. Solar irradiance is dependent on the latitude and the local incident solar radiation, whereas low-grade geothermal resources could be utilized to deliver energy needs at temperatures below $120{ }^{\circ} \mathrm{C}$ (Fox et al. [1]). In order to address the imbalance of demand and supply, effective technologies such as thermal energy storage (TES) play a major role in storing thermal energy for use at a future time. The stored thermal energy can then be used for providing thermal comfort in work environment, promoting energy conservation and improving operational life of electronics, etc. Thermal energy can be stored primarily as sensible heat storage (SHS) or latent heat storage (LHS) and chemically using chemical heat storage (CHS) methods. SHS utilizes the specific heat capacity of the storage material to increase the temperature of the substance during charging, whereas LHS relies on absorption of heat at a constant temperature during phase change. 
Thermo-chemical storage systems are based on the energy captivated/emitted during a breaking/reforming of molecular bonds in a reversible chemical reaction change.

In this study, focus is placed on the storage of thermal energy as latent heat which takes place by changing the phase of the material. Such energy storage materials are called Phase Change Materials (PCM) that include both organic and inorganic substances. Among a variety of PCM (fatty acids, salt hydrates, alcohols, etc.), as discussed by Pielichowska and Pielichowski [2], paraffin waxes have been the most commonly-used organic PCM. High latent heat of fusion, low melting temperature, no supercooling during phase change, and good stability when subjected to multiple cycles of charging and discharging make paraffin waxes very desirable for many applications. However, paraffin waxes, with a chemical formula of $\mathrm{C}_{n} \mathrm{H}_{2 n+2}$, possess one unwelcomed property: a low thermal conductivity, thus limiting the rates at which energy can be added to and extracted from the material. As a consequence, attempts to increase this thermophysical property have been the major focus of many researchers over the years by insertion of fixed, non-moving structures such as metal fins and foams (Fan and Khodadadi [3]) or more recently through suspension of various types of highly conductive nanostructures (Khodadadi et al. [4]). Colloidal suspensions of nanoparticles can also be used to improve other thermophysical properties of the PCM, such as supercooling, specific heat, etc. Focusing on improving thermal conductivity of PCM through dispersion of nanostructures, this novel approach only started a few years ago. Back in 2007, Khodadadi and Hosseinizadeh [5] reported results of a computational model showing the improvement of the functionality of the PCM through dispersion of nanoparticles. The model nanoparticle-enhanced phase change materials (NePCM) exhibited reduction in its freezing time period in comparison to the base material. Since then, many researchers have expanded on this idea and an abundance of journal papers 
were published on NePCM [4] and their applicability for thermal management, waste heat recovery, etc.

In this paper, the objectives were the preparation of the NePCM of ultra-stable colloidal solution of metallic silver $(\mathrm{Ag})$ nanoparticles $(0,1,2,3.5,5,6.5,8$ and $10 \mathrm{wt} \%)$ in eicosane $\left(\mathrm{C}_{20} \mathrm{H}_{42}\right)$ following three different solidification schemes: ice-water bath, room temperature and oven solidification approaches. In addition, determination of the composites' thermal properties such as thermal conductivity, latent heat and melting point using the transient plane source technique and differential scanning calorimetry was of interest. Finally, the dependence of thermal conductivity of the NePCM on the loading of Ag nanoparticles, the samples' temperature and the specific method of freezing were all investigated.

\section{Prior Research Studies on Pure Eicosane and Silver Nano-Structures Dispersed in PCM}

Before going in depth in the present study, a summary of thermal conductivity measurements on pure eicosane will be discussed. Eicosane, with a melting temperature of 36.4 ${ }^{\circ} \mathrm{C}$, belongs to the family of alkanes (commonly known as Paraffins) and studies of these materials date back many decades. Rastorguev et al. [6] measured the thermal conductivity of pure eicosane in the liquid state using the steady-state heated-filament technique. Thereafter, Griggs and Yarbrough [7] conducted experiments under the solid-state condition using an unguarded radial-heat flow apparatus. To date, more than 20 papers have been published on eicosane focusing on its thermal conductivity, heat transfer properties, crystallization, morphology, microstructure, etc. However, due to the focus of this study on thermal conductivity, 10 relevant papers were considered and the thermal conductivity data of pure eicosane in both solid and liquid states from these publications were extracted and are listed in 
Tables 1 and 2, respectively. Measured thermal conductivity of the pure eicosane samples in both liquid and solid states are presented in Figure 1. Values of the thermal conductivity higher than $0.5 \mathrm{~W} / \mathrm{mK}$ have been excluded for clarity, however those few omitted data are given in Table 1. The thermal conductivity data of pure eicosane solid samples of the present study (entry of Al Ghossein [14] in Table 1) correspond to the room temperature preparation route that will be discussed in the experiment section below. In the solid state, for measurements at temperatures less than $36.4{ }^{\circ} \mathrm{C}$, agreement exists between the thermal conductivity values reported by Stryker and Sparrow [9], Nabil [11] and measurements in this study (Al Ghossein [14]). Thermal conductivity values in this study and that of Nabil [11] were measured using the transient plane source (TPS) technique, a transient method that allows data to be collected in a few minutes, and sometimes as short as 2.5 seconds. On the other hand, Stryker and Sparrow [9] utilized the steady-state method; a technique where the user must wait for a long period of time in order for the test samples to attain thermal equilibrium. However, when comparing the data of the current study to those of Griggs and Yarbrough [7], Yarbrough and Kuan [8], Fang et al. [12] and Velez at al. [13], a discrepancy is observed in that the measured thermal conductivity decreased as the temperature of the sample increased, whereas in our tests, thermal conductivity was generally directly proportional to temperature. Griggs and Yarbrough [7] and Yarbrough and Kuan [8] credited the decreasing thermal conductivity to the unguarded radial heat flow apparatus leading to a $20 \%$ error in measurements because of the changing temperature of the sample. On the other hand, in the liquid state (Table 2), all measured data exhibited a decrease in thermal conductivity as the temperature of eicosane increased with Velez et al. [13] attributing the decline of thermal conductivity to the change in density, typical of first order phase transition. Measurements of Rastorguev at al. [6] exhibited similar trends. 
Regarding metal-based nanoparticles that were investigated for utilization in thermal energy storage systems, such nanostructures generally consisted of silver, copper, aluminum, or oxides such as magnesium oxide, copper oxide, alumina and titanium oxide (Khodadadi et al. [4]). In this project, metallic silver nanoparticles have been suspended in the PCM to investigate the change in thermal properties of the NePCM samples. Previously, other researchers have used metallic silver or silver oxide as nano-enhancers due to their stability, good dispersion within the PCM and very high thermal conductivity compared to other metals. A listing of the data of silver nanostructure-enhanced PCM is summarized in Table 3 and also shown in Figure 2. Zeng et al. [15] introduced silver nanowires (10-30 nm diameter and length of 5-15 microns) into 1Tetradecanol (TD). Several 1-Tetradecanol/Ag NW composites with different mass loading $(9.09,23.08,37.58,46.08$ and $62.73 \mathrm{wt} \%)$ of Ag nanowires were prepared using ultrasonication. The thermal conductivity was measured using the transient plane source technique at room temperature. Results showed a relatively linear increase in thermal conductivity of the composite as the concentration of the Ag nanowires increased (data are listed in Table 3 but excluded from Figure 2 since the reported weight fractions are exceedingly high compared to those reported by other studies). Parameshwaran, Jayavel and Kalaiselvam [16] prepared composites (0.1, 0.5, 1, 2 and $5 \mathrm{wt} \%)$ of silver nanoparticles (AgNP) and organic ester phase change material. Thermal conductivity was measured using the Flash Laser Analysis (LFA) method. Parameshwaran, Dhamodharan and Kalaiselvam [17] prepared hybrid nanocomposite phase change material (HyNPCM) by suspending silver-titania $\left(\mathrm{AgTiO}_{2}\right)$ nanoparticles $(63 \mathrm{~nm}$ diameter) into pure PCM, dimethyl adipate $\left(\mathrm{C}_{8} \mathrm{H}_{18} \mathrm{O}_{4}\right)$. The measured thermal conductivity increased as the mass fraction of the silver-titania nanoparticles increased from 0.08 to $1 \mathrm{wt} \%$. Parameshwaran et al. [18] also examined the thermal conductivity of suspended silver-titania 
nanoparticles into the pure PCM ethyl trans-cinnamate $\left(\mathrm{C}_{11} \mathrm{H}_{12} \mathrm{O}_{2}\right)$. Using the LFA technique again, thermal conductivity was recorded for various mass fractions $(0.1,0.5,0.8,1$ and 1.5 wt $\%$ ) of nanoparticles, and results illustrated an increase in thermal conductivity as the mass fraction of the nanoparticles increased. Most recently, Molaba et al. [19] published results of silver nanoparticles (diameter of $30-50 \mathrm{~nm}$ ) added to a PCM blend of isotactic polypropylene (iPP)/wax. The authors prepared silver-enhanced iPP/wax following two different approaches, i.e. slowly-cooled samples and quenched-in-ice-water composites. Thermal conductivity data obtained using the transient plane source technique indicated that samples that took longer to solidify exhibited a higher value of thermal conductivity due to the higher crystallinity occurring for a low transition phase. For both groups of samples prepared following the two approaches, as the concentration of silver increased, thermal conductivity increased up to a $4 \mathrm{wt} \%$ loading of nanoparticles, after which the values decreased. The authors attributed the decrease in thermal conductivity of samples with a $5 \mathrm{wt} \%$ loading to the rise in agglomeration and the lack of good dispersion of Ag nanoparticles. Still, values at $5 \mathrm{wt} \%$ were higher than the pure iPP/wax, while the highest enhancement was obtained for a loading of $4 \mathrm{wt} \%$ of $\mathrm{Ag}$ nanoparticles. The measured thermal conductivity ratios of silver-based nanostructure-enhanced PCM at room temperature as a function of the mass fraction of the nanoparticles reported by others [16-19] and a typical data from present study [14] are plotted in Figure 2. Various samples exhibited a linear increase in thermal conductivity as the loading of the nanostructures increased. The highest enhancement of thermal conductivity was obtained by Parameshwaran, Dhamodharan and Kalaiselvam [17] using $\mathrm{AgTiO}_{2}$ nanoparticles, showing an improvement of approximately $237 \%$. The data of Molaba et al. [19] and Al Ghossein [14] are banded similarly and will be discussed further below. 


\section{Preparation of the Silver-Based NePCM Samples}

Preparation of the NePCM samples with suspensions of in-house copper oxide nanoparticles in eicosane was discussed in great detail by Nabil [11], and Nabil and Khodadadi [20]. That procedure took several steps of preparation and cleaning before dispersion of $\mathrm{CuO}$ nanoparticles. The adopted procedure in the present study was a one-step straightforward synthesis that takes about 1 hour. Eicosane $\left(\mathrm{C}_{20} \mathrm{H}_{42}\right)$ with a melting point of $36.4{ }^{\circ} \mathrm{C}$ was selected as the base PCM. Eicosane with a purity of 99\%, purchased from Sigma-Aldrich, is a white-colored paraffin, with a latent heat (heat of fusion) of $247.5 \mathrm{~kJ} / \mathrm{kg}$, a boiling point of 345.1 ${ }^{\circ} \mathrm{C}$ and liquid and solid densities of 789 and $840 \mathrm{~kg} / \mathrm{m}^{3}$, respectively (Freund et al. [21]). Silver (Ag) was chosen as the nanoparticle enhancers. Silver, possessing good thermal stability and the highest thermal conductivity of all metals, justified its choice of use (Lide [22]). Silver neodecanoate $\left(\mathrm{C}_{10} \mathrm{H}_{19} \mathrm{O}_{2}\right)$ was purchased from Strem Chemicals and served the role of precursor to the silver nanoparticles. The high purity of silver precursor and eicosane, 97\% and 99\%, respectively, meant that drying of the chemicals was not necessary. Transmission electron microscopy (TEM) images (Hossain and Mills [23]) exhibited that the nanoparticles were nearly spherical with a diameter of approximately $5.36 \mathrm{~nm}$ (Figure 3). Oleoyl Sarcosine (OS) was obtained from TCI America and was used as a stabilizer for the particles. The standard procedure for the preparation of Ag colloids was described in detail by Darvin et al. [24]. Synthesis of metallic silver particles of desired concentration involves addition of silver neo-decanoate, a white powder, that was added to a solution containing OS in eicosane preheated to $160{ }^{\circ} \mathrm{C}$ in an oil bath under vigorous stirring. The temperature was maintained at that value until the reaction was completed ( 40 minutes). The concentration ratio of metallic Ag to stabilizer (OS) was kept constant for all loading of $\mathrm{Ag}$ in eicosane. In this case, the concentration ratio of $\mathrm{Ag}$ to $\mathrm{OS}$ 
was 1.25 for all samples. The constant concentration ratio helps us to maintain similar particles size distribution for all Ag samples and protects the particles from agglomeration at very high concentration. In order to check the long-term stability of the liquid samples prepared, specimen of different mass fractions $(1,5$ and $10 \mathrm{wt} \%)$ were placed inside a vacuum oven at a temperature of $50{ }^{\circ} \mathrm{C}$ for a time period of 1 week and no precipitation was visually observed for all three Ag/eicosane samples. In preparing the solid specimen, a certain amount of colloids was poured into custom-made aluminum molds; the molds have dimensions of $2.54 \mathrm{~cm}$ in diameter and $0.9525 \mathrm{~cm}$ in height. Upon dispensing the liquid samples in the molds, phase transition was achieved by subjecting the samples to three different methods of solidification. The three distinct solidification methods entailed: 1. exposing the aluminum molds to an ice-water bath, 2. leaving the molds in the laboratory at room temperature, and 3. placing the molds inside the oven with the oven being turned off. In effect, the various solidification schemes differed in the period of time the specimen were allowed to freeze at different temperatures while being held at atmospheric pressure. For the first method, the aluminum molds holding the NePCM samples were directly in contact with a bowl of crushed ice, and the duration of the freezing time was about 5 minutes. As for the second route, solidification took almost 30 minutes. Finally, for the third and last scheme of freezing of specimen, the vacuum oven (Fischer Scientific, Isotemp® Vacuum Oven Model 281A) was heated to $50{ }^{\circ} \mathrm{C}$ and then turned off with the samples inside; this route took almost 3 hours to be completed. Upon solidification of the samples, the samples were removed from the aluminum molds and pairs of disks with different surface morphologies were obtained. Photographs of the pure paraffin, $1 \mathrm{wt} \%$ and $10 \mathrm{wt} \% \mathrm{Ag} /$ eicosane are shown in Figure 4. When the mass loading of Ag increased, the color of the samples changed from black to purple to blue; however, after applying heat to the samples during thermal conductivity 
determination tests, black color persisted as the dominant color of all the samples. Due to the requirements imposed by the transient plane source theory in having a tight contact between the heater/sensor element and the two samples and the variation of the surface morphology of each sample, two grades of sand paper -beginning with grade 300 and finishing with grade 400- were used to flatten the sides of the disks before subjecting these to thermal conductivity measurements. The average mass of the samples was about 4 grams.

\section{Thermal Conductivity Measurements}

There are numerous ways to measure the thermal conductivity of a material such as the steady-state method and the transient methods. Depending on the state, type and form of the material under consideration, an appropriate method is chosen. For liquid samples, in order to avoid onset and persistence of natural convection during the measurements, transient methods are favored due to its desirable feature of acquiring data over a short time duration compared to the steady-state methods, where one must wait a long time for establishment of a stable temperature gradient within the sample.

\subsection{Instrumentation}

Thermal conductivity measurements of the Ag/eicosane NePCM samples were performed using the transient plane source technique at different temperatures ranging from 10 to $35^{\circ} \mathrm{C}$ or up to the melting point of the specific sample, whichever temperature was reached first. The instrument used, a Hot Disk Thermal Constants Analyzer (TPS 500), can measure the thermal conductivity of the material along with other thermophysical properties (thermal diffusivity, specific heat, etc.) in a period of time as short as 2.5 seconds. Another advantage of this instrument is its low uncertainty (reported to be at maximum $2 \%$ by the manufacturer). 
Based on the theory of the Transient Plane Source technique, the TPS method utilizes a sensor element in the shape of a double spiral. The TPS sensor serves a dual purpose: it functions as a planar heat source for increasing the sample's temperature and it serves simultaneously as a resistance thermometer for recording the transient temperature rise versus heating time. Two sensor elements with different outer radii were available and for this study the sensor with the smaller radius of $3.189 \mathrm{~mm}$ was used. The choice of the sensor element with a smaller radius is due to the dimensions of the NePCM samples and their expected low thermal conductivity value. The sensor of choice is made of a $10 \mu \mathrm{m}$ thick Nickel-metal double spiral and is coated with the polyimide "Kapton" to provide protection of the sensor's shape, to give it mechanical strength and to keep it electrically-insulated. Since the Ag/eicosane samples are in the solid phase, the encapsulated Ni-spiral sensor is to be sandwiched between two identical samples. An assumption of the theory governing the operation of the TPS technique is that the sensor is located in an infinite material, which in practice means that the transient recording's total time is limited by the presence of the outside boundaries of the sample. In other words, the thermal wave generated by the sensor must not be allowed to reach the outside boundaries of the samples. As a result, great care must be taken in defining the "thermal probing depth", thus making sure the travel distance of the wave does not exceed the size of the samples during the transient recording. After setting the measurement time of the experiment, 200 temperature data points are recorded at equal time intervals, and from these recordings, the relation between the sample temperature and time is established. Parameters such as the applied heating power to increase the temperature of the spiral, the measurement time for recording the 200 temperature data and the choice of the sensor's size that affect the measurement were carefully selected to optimize the settings of the measurements and obtain accurate results. In choosing the appropriate sensor, the thickness of 
the sample must not exceed the radius of the sensor; a parameter that need to be satisfied is that of the Total to Characteristic Time (TCT) which is defined as $r^{2} / \alpha$, where $r$ is the radius of the sensor in $\mathrm{mm}$ and $\alpha$ is the thermal diffusivity of the sample in $\mathrm{mm}^{2} / \mathrm{s}$. The instruction manual recommends a range of 0.33 and $1 \mathrm{~s}$ for a measurement and if that range is not satisfied, the sensor and/or test time must be changed. Another criterion resides in the probing depth of the thermal wave that is typically the shortest distance from the tip of the sensor to the outer boundary of the sample. In other words, it relates to the thickness of the sample. The theory behind the TPS technique assumes an infinite material with no boundaries, but since experimentally this is not practical, one must make sure that the available probing depth is always greater than the measured probing depth. If that is not the case, then the test time must be either shortened or extended depending on the value of TCT. Other important criteria, related to the choice of the heating power, are the temperature increase between the first and last point used in the data analysis (must be between 0.4 and $4 \mathrm{~K}$ ) and the mean deviation of the points (a deviation with a magnitude of $10^{-4} \mathrm{~K}$ is typical). If the results did not fall in those ranges, then a new heating power must be chosen.

\subsection{Experiment Details}

As for the experimental setup, two aluminum cold plates (LYTRON Co., Woburn, MA, Model CP20G01) that served as means of controlling the reported measurement temperature were utilized. A pair of identical Ag/eicosane composites was placed on the two cold plates, with the TPS sensor sandwiched in between the two disks and perfectly centered. To assure thermal contact between the cold plates and the samples, green-colored $3 \mathrm{~mm}$ thick layers of Gap Pad ${ }^{\circledR}$ 300 S30 (The Bergquist Company, Minnesota, USA) with a thermal conductivity of $5 \mathrm{~W} / \mathrm{mK}$ were placed between the specimen and the cold plates. Also, to reduce heat loss to the 
environment, Styrofoam ${ }^{\circledR}$ was used to insulate the experimental setup from the ambient temperature. Two adjustable side screws and a circular metal plate were also used to keep the sensor at a horizontal position between the two samples. Another screw at the top of the setup was used to compress the two plates together to impose uniform pressure on the entire assembly. The liquid flow passageways of the aluminum cold plates were connected to the ports of a programmable bath circulator. The bath (TP-502P, Brookfield, Middleboro, MA) with a temperature stability of $0.01{ }^{\circ} \mathrm{C}$ and a pumping rate varying from 0.006 to $0.015 \mathrm{~m}^{3} / \mathrm{min}$ was used to control the temperature of the working fluid. The working fluid, a distilled water/ethylene glycol 1:1 mixture with a freezing point of about $-34{ }^{\circ} \mathrm{C}$, was employed in order to attain the bath temperature below ice point $\left(0^{\circ} \mathrm{C}\right)$. Due to the internally-crisscrossed finned structure of the aluminum cold plates that promotes great mixing, the temperatures of the two plates can be adjusted quickly to the temperature of the working fluid. In addition to the internal temperature sensor of the bath, an external 2-wire thermistor (GE, Model A733FCSP60BT103M, St. Marys, PA, accuracy of $0.01{ }^{\circ} \mathrm{C}$ ) was also used to monitor the bath temperature and that of the samples. The thermistor was placed between the two samples in the middle of the two cold plates, and a waiting time period of 60 minutes elapsed in order to establish thermal equilibrium at each measured temperature. The temperature reading of the thermistor served as the measurement temperature that is reported. The measurement temperature was increased in increments of $5{ }^{\circ} \mathrm{C}$ for the $10-30{ }^{\circ} \mathrm{C}$ range. After that, the temperature was raised by $1{ }^{\circ} \mathrm{C}$ at a time to further resolve the measurement temperature near the melting point of the respective sample. The TPS500 was operated with a heating power of 0.1 $\mathrm{W}$ for duration of 5 or 10 seconds, and as the temperature of the samples increased, the applied power was decreased to $0.03 \mathrm{~W}$, while the measurement time reached a maximum of 10 seconds. 
As for the probing depth, it was measured to be about $3 \mathrm{~mm}$, never exceeding the available probing depth $(5 \mathrm{~mm})$ of the solid disks. These settings proved to be the most accurate and provided the best reproducibility of the 200 data points collected for each run.

\subsection{Effect of the Contact Resistance on TPS Measurements}

The uniform pressure applied by the top screw on the upper cold plate holding the samples plays a major role in recording the correct values of thermal conductivity of the composites. The screw needs to be positioned tightly to the plate to ensure no air is trapped between the samples and the sandwiched heater/sensor (note that air might even circulate). However, by ensuring a very tight grip of the plates and the sensor, the sensor might be damaged. As a result, a low thermal contact resistance is desirable and a middle ground must be attained. Based on the investigation of Nabil [11], for a number of turns equal to or greater than 0.5 turns, thermal conductivity data showed an asymptotic behavior. Consequently, all the measurements in this project were recorded at exactly 1 full turn of the screw.

\section{Latent Heat and Melting Point Measurements}

The latent heat (heat of fusion) and the melting point of the eicosane-based NePCM samples containing silver nanoparticles were investigated utilizing differential scanning calorimetry (DSC).

\subsection{Instrumentation and Experiment Details}

Differential thermal analysis was carried out on the FP90 Central Processor/FP99 Software in the temperature range of -100 to $600{ }^{\circ} \mathrm{C}$. The FP90 (Mettler-Toledo International Inc., Columbus, Ohio) serves as the control unit and communication system of the thermal system. After attachment of the measuring cell FP84HT to the control unit FP90, several thermophysical properties can be measured such as the heat of fusion $(\Delta H)$, specific heat 
capacity $\left(C_{p}\right)$ and melting point of the material $\left(T_{m}\right)$. The FP84HT Hot Stage simultaneously allows visual observation of the sample and measurement of the heat flows following the DSC principle. The hot stage can be utilized in the range of -60 to $375{ }^{\circ} \mathrm{C}$ with an accuracy of $\pm 0.6{ }^{\circ} \mathrm{C}$. The instrument was calibrated using Indium (99.999\%) and Benzophenone. The tested NePCM samples weighed in the range of 4-8 $\mathrm{mg}$ and were subjected to four (4) cooling and heating cycles at a ramping rate of $5{ }^{\circ} \mathrm{C} / \mathrm{min}$ (starting at $10{ }^{\circ} \mathrm{C}$ and ending at $60{ }^{\circ} \mathrm{C}$ ) lasting a period of 10 minutes.

\section{Results and Discussion}

For all the NePCM samples of different mass fractions of silver nanoparticles, 3 thermal conductivity runs were conducted at each measurement temperature and the average of the three runs are reported. The standard deviation was on average $1.33 \%$ for all the samples regardless of the solidification method. For all reported figures, except for Figure 11, the values of the measured thermal conductivity near the respective melting temperature are excluded so as to maintain clarity of the presented data and graphics. A detailed analysis of the results is discussed below.

\subsection{Differential Scanning Calorimetry and X-Ray Diffraction Results}

The reported data for the heat of fusion and the melting point of the NePCM composites were the average of three runs and were obtained from the third heating cycle (reproducibility of $\pm 5 \%$ ). The DSC data for samples prepared following the room temperature solidification approach are tabulated in Table 4. The experimental and theoretically-predicated values of the phase change temperature of the pure eicosane and the $\mathrm{Ag}$ /eicosane NePCM samples prepared following the room temperature approach are plotted in Figure 5. Moreover, the DSC curves of pure eicosane, 1, 2 and $3.5 \mathrm{wt} \% \mathrm{Ag} /$ eicosane samples, and the DSC curves of 5, 6.5, 8 and 10 
wt\% Ag/eicosane composites are plotted in Figures 6 and 7, respectively. For the experimental results, the temperature marking the transition between the solid and liquid states was taken at the peak of the DSC curves, whereas the latent heat was evaluated as the integrated area under the curve. Measured values of the latent heat and the melting point of the NePCM samples are inversely proportional to the concentration of the additives. As the particles' loading increased, the melting point of the NePCM decreased slightly. A consequence of the variation of the melting point of the composites is the need to conduct the thermal conductivity measurements for a different applicable range of temperature when getting close to the respective melting point of the specific sample. Going through the data in Table 4, the experimental results for the melting temperature are in great agreement with the values based on theoretical predictions. Equation (1), given by Noggle [25], was used to calculate the theoretical values of the melting temperature:

$T_{m}=T_{m}^{\circ}-K_{f} m$,

where $T_{m}, T_{m}^{\circ}, K_{f}$ and $m$ denote the melting temperature of the Ag/eicosane composite $\left({ }^{\circ} \mathrm{C}\right)$, the literature value of the phase change temperature of the pure solvent (melting point of pure eicosane is $36.4{ }^{\circ} \mathrm{C}$ according to Freund et al. [21]), the molal freezing-point-depression constant of eicosane $(3.23 \mathrm{kgK} / \mathrm{mol})$, and the molality of the composite ratio of the number of moles of the solute to the mass of the solvent $\left(m=\frac{n_{\text {silver nanoparticles }}}{m_{\text {eicosane }}}\right)$, respectively. Due to the absence of literature data on the molal freezing-point-depression constant of eicosane, the following equation, also introduced by Noggle [25] was adopted:

$K_{f}=\frac{0.1 R T_{m}^{\circ}}{\Delta H^{o}}$

where $R$ is the universal gas constant $(8.314 \mathrm{~J} / \mathrm{molK})$ and $\Delta H^{o}$ stands for the latent heat of fusion of the pure sample (247.5 J/g). Depression of the melting point with respect to Ag additives is 
clearly observed in Figure 5. Presence of the particles should not have any effect on lowering of the freezing point. However, the stabilizer, i.e. OS has direct interaction to the solvent. As the concentration ratio of $\mathrm{Ag}$ precursor to $\mathrm{OS}$ (1.25) was kept constant for all $\mathrm{Ag}$ samples, concentration of OS increases with increasing Ag loading. From Figure 5 it is very clear that the experimental values follow the similar trends of lowering of freezing points as theoretical values. However, OS-based colloidal Ag/eicosane is not a true solution and the bound OS on metal surface have less effect on lowering of the melting points compared to unbound or free ligands of OS. Therefore, the active molality of free OS is much less than the calculated molality of OS in $\mathrm{Ag} /$ Eicosane. Since the numbers of active moles are always lower in every case than the theoretically-calculated values therefore, we observe small depression of melting points than expected.

As for the theoretical heat of fusion data, great care must be taken in converting the experimental values of the mass fraction $\left(\emptyset_{w t}\right)$ of the Ag nanoparticles to the volume fraction $\left(\emptyset_{v o l}\right)$ of the fillers in the colloids used exclusively in theoretical models. Although the weight fraction of the nano-additives doesn't change during solidification of the samples, the volume fraction of the liquid and solid samples are different since the base PCM shrinks during phase change because of the higher density of eicosane in the solid phase $\left(\rho_{s}=840 \mathrm{~kg} / \mathrm{m}^{3}\right.$ and $\rho_{l}=789$ $\mathrm{kg} / \mathrm{m}^{3}$ ). Assuming a two-component system, Equation (3) was used to convert the mass fraction of the nanoparticles within the prepared liquid samples to the volume fraction of the samples in the solid phase:

$\emptyset_{v o l}=\frac{\emptyset_{w t} \rho_{c}}{\emptyset_{w t} \rho_{c}+\left(1-\emptyset_{w t}\right) \rho_{d}}$

where $\rho$ stands for the density of the discrete (subscript $d$, i.e. Ag nanoadditives) and the continuous (subscript $c$, i.e. eicosane) phases and $\phi_{w t}$ is the weight fraction of the 
additives. In using the above formula, the density of the base PCM eicosane in the solid phase must be used. Then, Equation (4) was used to determine the theoretical values of the latent heat according to a simple mixture rule (Khodadadi and Hosseinizadeh [5]):

$\Delta H=\left(1-\emptyset_{v o l}\right) \frac{\rho_{c}}{\rho_{e f f}} \Delta H^{o}$,

where $\rho_{\text {eff }}$, the effective density of the Ag/eicosane composites, is given by:

$\rho_{e f f}=\left(1-\emptyset_{v o l}\right) \rho_{c}+\emptyset_{v o l} \rho_{d}$

and $\Delta H$ stands for the heat of fusion of the Ag/eicosane composites $(\mathrm{J} / \mathrm{g})$ for each loading of silver nanoparticles. The predicted values of the heat of fusion of $\mathrm{Ag} / \mathrm{eicosane}$ composites are given in Table 4. Unlike the melting point data, a discrepancy is observed between the experimental and theoretical values of the latent heat. As can be seen from Figures 6 and 7, a noticeable drop occurs in the experimental heat of fusion values reaching a value as low as 78.3 $\mathrm{J} / \mathrm{g}$ for a mass loading of $10 \mathrm{wt} \%$. It must be noted that Eq. (4) is an approximation of the theoretical latent values due to the absence of a complete definition of heat of fusion of colloids in the literature. Similar to the decrease of the melting temperature, the decrease in the latent heat of fusion of the samples is due to the colligative properties of the composites. Another explanation behind this observation could be the unbound ligands of OS which are welldispersed in eicosane affecting eicosane crystal structure and grain size. If the solvent-ligand attraction force overcomes solvent-solvent interaction, then the required de-crystallization energy will be expected to be very low.

Experimental thermograms of the melting and crystallization of pure eicosane prepared following the room temperature solidification protocol and that of Kolesnikov and Syunyaev [26] who used a ramping rate of $1{ }^{\circ} \mathrm{C} / \mathrm{min}$ are presented in Figure 8a-b. The present DSC results suggest that as the temperature of the sample was raised, melting of eicosane was characterized 
by one exothermic peak, whereas the endothermic reaction upon cooling was marked by two distinctly-separated peaks. When comparing our results to a study investigating the phase transformation of both eicosane $\left(\mathrm{C}_{20} \mathrm{H}_{42}\right)$ and octadecane $\left(\mathrm{C}_{18} \mathrm{H}_{38}\right)$ (Kolesnikov and Syunyaev [26]), a disagreement is observed in the heating segment of the cycle. These authors reported two neighboring peaks (shown as an inset in Figure 8b), where the first peak was ascribed to a solidsolid phase transition and the second peak corresponded to a solid-liquid phase change, analogous of melting of eicosane. It was claimed [26] that the first of the two peaks observed during the cooling portion of the cycle corresponds to crystallization, while the second peak corresponds to a structure modification (transition from the triclinic structure to the hexagonal structure shown in Figure 8c). Paraffins, at temperatures below their melting point, are always crystalline whether they exist as solitary chemical compounds or in mixtures (Freund et al. [20]). As noted by Nyburg and Potworski [27], the n-alkanes $\mathrm{C}_{\mathrm{n}} \mathrm{H}_{2 \mathrm{n}+2}$ for $n \geq 6$, crystallize in four ways depending on the purity and parity of $n$ :

1. triclinic, for $n$ (even) $\leq 26$ (Muller and Lonsdale [28]),

2. monoclinic, if the paraffin is pure, for $26 \leq n$ (even) $\leq 36$ (Broadhurst [29]),

3. orthorhombic, if the paraffin is not pure, for $26 \leq n$ (even) $\leq 36$ (Broadhurst [29]),

4. orthorhombic, $11 \leq n$ (odd) $\leq 39$ (Piper and Malkin [30]).

In order to verify the presence of crystalline structures in our Ag/eicosane samples, X-ray diffraction (XRD) patterns were obtained using the Bruker D-8 Discover system housed in the Materials Engineering Department at Auburn University. This instrument is a two-circle goniometer with an angular precision of $\pm 0.0001^{\circ}$ and an angle measuring accuracy of $0.005^{\circ}$. The XRD patterns were recorded using $\theta / 2 \theta$ geometry with $2 \theta$ ranging from $5^{\circ}$ to $90^{\circ}$ in steps of 
$5^{\circ}$. Diffraction scans were recorded for a stationary solid sample prepared following the room temperature freezing scheme, and all measurements were carried out under ambient conditions. X-ray diffraction patterns of pure eicosane, 1 and $10 \mathrm{wt} \% \mathrm{Ag}$ /eicosane NePCM composites at room temperature, along with an inset of the XRD pattern of silver are plotted in Figure 9. The X-ray diffraction pattern for pure and metallic silver nanoparticles shown as an inset in Figure 9 was obtained upon preparation of Ag in PEG (polyethylene glycol) samples (Hossain and Mills [23]) using the Ultima IV X-ray Diffractometer (Rigaku, Texas, USA). The sharp and intense peaks in Figure 9 are an indication of the crystalline structure of the paraffin, proving the formation of crystals during the preparation of the NePCM. As for the presence of silver nanoparticles, the X-ray diffraction system was not able to precisely identify the peaks attributed to silver for all four lattice planes, possibly due to the their small size $(\sim 5.36 \mathrm{~nm})$ and their low concentration in the NePCM composites. However, in Figure 9, at $10 \mathrm{wt} \%$ loading of $\mathrm{Ag}$ nanoparticles, a broad range of x-ray diffraction could be observed at $38^{\circ}$, an indication of the presence of silver nanoparticles indexed to the dominant (111) lattice plane.

\subsection{Thermal Conductivity Data for Ice-Water Bath Solidification Samples}

The measured thermal conductivity of solid pure eicosane and Ag/eicosane composites that were prepared following the ice-water bath route are presented in Figure 10. The thermal conductivity generally increased as the temperature of the samples increased. This result differed from the findings of Nabil and Khodadadi [20] who reported that the thermal conductivity of $\mathrm{CuO} /$ eicosane composites were independent of temperature. Parallel to Fan [10] and Nabil [11] who worked with $\mathrm{CuO} /$ eicosane composites, a sharp rise in the thermal conductivity value was recorded when the samples' temperature was close to the respective melting point of the samples. A clear explanation to the occurrence of this jump has not been found yet, but efforts 
are presently being made to explain this behavior. This temperature range, where the sample has not yet completely melted, is a non-equilibrium state. If studies or efforts are made to keep the sample in that state, the utility of the NePCM in relation to charging of the medium would be very desirable for thermal energy storage applications. Furthermore, a rise in thermal conductivity is observed as the mass fraction of the nanoparticles increases for all measured temperatures up to the $2 \mathrm{wt} \%$ loading. For higher values of particle loadings, a non-monotonic relation existed between the loading of the NePCM and its thermal conductivity regardless of the temperature. In effect, values of thermal conductivity for the 3.5 and 5 wt $\%$ samples were consistently lower than the values at a loading of $2 \mathrm{wt} \%$. Then at $6.5 \mathrm{wt} \%$ and beyond, thermal conductivity starts increasing again reaching its greatest value for a mass fraction of $10 \mathrm{wt} \%$ ( $0.5481 \mathrm{~W} / \mathrm{mK}$ corresponding to $35.27 \%$ enhancement compared to pure eicosane).

In addition to the trends discussed above, the ice-water bath solidification method consistently exhibited the lowest values of thermal conductivity when compared to the values obtained for samples prepared following the room temperature and oven solidification routes as illustrated in Figure $11\left(10 \mathrm{wt} \%\right.$ samples and melting temperature of $33.5{ }^{\circ} \mathrm{C}$ for the room temperature sample). As for comparisons of thermal conductivity values among different freezing schemes for the remaining NePCM composites with different loadings of silver nanoparticles, the reader is directed to $\mathrm{Al}$ Ghossein [14]. A possible explanation behind this phenomenon is the presence of air pockets trapped inside the sample during its freezing. The samples solidified under room temperature and in an ice-water bath are susceptible to greater retention of air pockets (voids) which will alter the sample and decrease the thermal conductivity of the NePCM. And since the ice-water bath technique is the quickest among the three methods, a lower thermal conductivity value was expected. 


\subsection{Thermal Conductivity Data for Oven Solidification Samples}

The measured thermal conductivity of the solid pure eicosane and Ag/eicosane composites that were prepared following the oven solidification method are presented in Figure 12. As in the case with the ice-water bath samples, specimen prepared following the oven solidification scheme exhibited a relation between temperature and the thermal conductivity; as the temperature of the sample increased so did the thermal conductivity regardless of the mass fraction of the nanoparticles. In addition to this trend, for the temperature range of $30-35^{\circ} \mathrm{C}$, the thermal conductivity rise is steep and that slope becomes more marked as the sample's temperature gets close to the respective phase change temperature. At that point, an abrupt rise in thermal conductivity is exhibited that is commensurate with findings for samples prepared using the previous method of freezing, and as also found by Fan [10] and Nabil [11] for their $\mathrm{CuO} /$ eicosane composites. Furthermore, a monotonic rise of thermal conductivity occurs up to the $2 \mathrm{wt} \%$ loading of Ag nanoparticles. Beyond that loading, a decreasing trend is detected up to $6.5 \mathrm{wt} \%$ followed by an augmentation of thermal conductivity values up to $10 \mathrm{wt} \%$. The highest value of thermal conductivity was achieved for this loading of nanofillers $(0.5862 \mathrm{~W} / \mathrm{mK}$, i.e. an enhancement of $28.95 \%$ compared to pure eicosane).

As for the $10 \mathrm{wt} \%$ loading of $\mathrm{Ag}$ nanostructures, thermal conductivity data measured for samples prepared following the oven solidification method showed the highest values when compared to the other two methods (Figure 11). Another potential explanation resides in the change of the microstructure of the NePCM and the time duration of the solidification process. A longer phase change time period would lead to formation of bigger micro-scale grains; therefore reducing thermal resistance layers leading to an increase of thermal conductivity. And as mentioned before, the absence of trapped gases and air voids in the samples solidified in the oven could also lead to the high values of thermal conductivity of NePCM. 


\subsection{Thermal Conductivity Data for Room Temperature Solidification Samples}

The measured thermal conductivity of the solid pure eicosane and Ag/eicosane composites that were prepared following the room temperature method are illustrated in Figure 13. Similar to what was mentioned above, thermal conductivities of these samples were dependent on the temperature of the samples, and when close to the specific melting point of each sample, a jump in thermal conductivity was obtained. In addition to the jump in thermal conductivity, values of thermal conductivity of the samples prepared following the room temperature route were higher than the ice-water bath samples but still lower than the samples prepared in the oven for most measurement temperatures (Figure 11). Focusing at one specific measurement temperature, there is an increasing trend up to $2 \mathrm{wt} \%$. Above this loading, a nonmonotonic relationship exists between the thermal conductivity of the sample and the particles loading, regardless of the temperature range studied, with the highest loading recorded at 10 wt $\%$. The thermal conductivity value for the sample prepared using the ice-water bath scheme for the $10 \mathrm{wt} \%$ loading was $0.8319 \mathrm{~W} / \mathrm{mK}$, while the value, at the same loading, recorded for the room temperature freezing sample was $0.8534 \mathrm{~W} / \mathrm{mK}$, and the greatest thermal conductivity of all samples was $0.8754 \mathrm{~W} / \mathrm{mK}$ measured following the oven solidification route.

The ratio of the thermal conductivity of the Ag/eicosane composites $\left(k_{\text {eff }}\right)$ to the thermal conductivity of pure eicosane (relative thermal conductivity), prepared under the room temperature protocol, and the theoretical values based on the Maxwell's model [31], have been calculated and illustrated in Figure 14. Maxwell's relation is given in Equation (6):

$k_{e f f}=k_{c}\left[\frac{k_{d}+2 k_{c}-2 \emptyset_{v o l}\left(k_{c}-k_{d}\right)}{k_{d}+2 k_{c}+\emptyset_{v o l}\left(k_{c}-k_{d}\right)}\right]$,

where subscripts eff, $c, d$ and $\emptyset_{\text {vol }}$ denote effective, continuous (base PCM eicosane), discrete (Ag nanoparticles), and the volume fraction of the nano-additive materials, respectively. It 
should be noted that the volume fraction of the solid samples were obtained using relation (3). There is no value in the literature for the thermal conductivity of the silver neo-decanoate, the precursor of the silver nanoparticles, so a thermal conductivity value of $429 \mathrm{~W} / \mathrm{mK}$ is adopted for $k_{d}$ (Yaws [32]). As discussed earlier, the experimental data clearly exhibit the non-monotonic dependence of the thermal conductivity on mass fraction, regardless of the measurement temperature. However, the predicted values of the relative thermal conductivity, given by the Maxwell model exhibit monotonic relations which are consistently below the measured values. This suggests that in our NePCM samples, the colloids were not ideally well-dispersed in the solution as modeled by Maxwell and agglomeration of nanoadditives were present, thus establishing a more effective thermally conductive network. Focusing on a specific measurement temperature, e.g. $T=31^{\circ} \mathrm{C}$, a non-monotonic relation, also observed for the other two methods of solidification, exists between the relative thermal conductivity and the mass fraction (Figure 14). Also, a dependence of the thermal conductivity on the measurement temperature was observed for any specific mass fraction and all the experimental data were greater than the Maxwell's prediction. In addition to that, the plot exhibits the steep thermal conductivity rise when the sample reaches a temperature in the range of $30-35^{\circ} \mathrm{C}$.

The Figure of Merit that quantifies the value and importance of the Ag nanoparticles and $\mathrm{CuO}$ nanoparticles (Nabil [11]) as a function of the mass fraction of the nano-structures, is illustrated in Figure 15. Ideally, for highly conductive nanofillers $\left(k_{d} \rightarrow \infty\right)$ and small volume fractions, the limit of the Figure of Merit based on the Maxwell's model is equal to 3. In this study, the Figure of Merit reached a value as high as 83, whereas the $\mathrm{CuO}$ nanoparticles exhibited a maximum value of 23 at $2 \mathrm{wt} \%$ loading of nanofillers, thus indicating that silver metallic nanoparticles are a more effective choice for thermal energy storage applications. 
Furthermore, even though the Figure of Merit decreases as the mass fraction of the nanostructures increases, the minimum value of about 19 in this research remains well above the Maxwell's model limit of 3. The Figure of Merit information for the experimental data of Molaba et al. [19] with silver nanoparticles is also shown in Figure 15. Similar to our data, the volume fraction of the solid samples were obtained using relation (3). The Figure of Merit of Molaba et al. [19] are in the range of 35-55 and exhibit a trend of a maximum around a value of $3.5 \mathrm{wt} \%$ compared to $2 \mathrm{wt} \%$ reported by Nabil [11] and Al Ghossein [14].

Finally, it should be noted that whereas the uncertainty associated with the TPS thermal conductivity data was estimated to be $5 \%$ of the measured value, there are also uncertainties associated with using the Maxwell relation. Uncertainty analysis was conducted for equations (3) and (5) in order to determine the dependency of these relations on the following parameters: density, thermal conductivity, mass fraction and volume fraction. A method to estimate the uncertainty in experimental results was presented by Kline and McClintock [33], a model that was followed by many researchers in estimating the uncertainty in their experimental data. This method is described in detail along with the results of its application to the two aforementioned equations by $\mathrm{Al}$ Ghossein [11].

\section{$\underline{\text { 7. Conclusions }}$}

To sum up the conclusions of this work, eicosane-based NePCM containing suspensions of $\mathrm{Ag}$ nanoparticles of different weight fractions (0,1, 2, 3.5, 5, 6.5, 8 and 10 wt\%) were prepared following three different solidification schemes. The NePCM colloids showed no

precipitation for all Ag loadings, and the samples were found to be stable for a long period of time. The Transient Plane Source (TPS) technique, along with a controllable bath/circulator to adjust the measurement temperature of the samples, was used to measure the thermal 
conductivity of the NePCM of different loadings at different temperatures below and near their respective melting temperatures. Results generally showed an increase in the value of thermal conductivity as the temperature of the solid sample increased regardless of the preparation route and the particles loading. Furthermore, when the measurement temperature was close to melting point, a sharp rise in thermal conductivity was observed for all NePCM samples. As for the different solidification protocols, the samples prepared utilizing the oven solidification route exhibited the highest values of thermal conductivity, while NePCM samples prepared following the ice-water bath scheme showed the lowest values because of the change in the microstructure of the samples and the possibility of presence of air voids. In addition to that, a non-monotonic relationship between the thermal conductivity and the mass fraction of the Ag nanoparticles was observed above a loading of $2 \mathrm{wt} \%$. Finally, DSC was used to measure other thermal properties such as the heat of fusion and the melting point of the NePCM. Experimental and theoretical data showed a decrease in the aforementioned properties as the additives' loading increased leading to the decrease in the number of molecules of the solvent eicosane in the samples. Due to the decreasing phase change temperature, the choice of the amount of silver nanoparticles to be added to the PCM depends on the type of application of the thermal energy storage material.

\section{$\underline{\text { Acknowledgements }}$}

The material in this study is based upon work supported by the US Department of Energy under Award Number DE-SC0002470 (http://www.eng.auburn.edu/nepcm). The first author acknowledges the Samuel Ginn College of Engineering and the Department of Mechanical Engineering at Auburn University for partial financial support of his College Fellowships. The first author also acknowledges financial support provided by the Alabama EPSCoR Program under the Graduate Research Scholars Program (Round 9). The third author acknowledges that the research leading to these results has received funding from the European Union's Seventh 
Framework Programme (FP7/2007-2013) under grant agreement no. PIRSES-GA-2013-610692 (INNOSTORAGE; http://www.innostorage.eu/). 


\section{$\underline{\text { References }}$}

[1] Fox, D. B., Sutter, D., and Tester, J. W., 2011, “The thermal spectrum of low-temperature energy use in the United States," Energy \& Environmental Science, 4, pp. 3731-3740.

[2] Pielichowska, K., and Pielichowski, K., 2014, "Phase change materials for thermal energy storage," Progress in Materials Science, 65, pp. 67-123.

[3] Fan, Liwu and Khodadadi, J. M., 2011, "Thermal conductivity enhancement of phase change materials for thermal energy storage: a review," Renewable and Sustainable Energy Reviews, 15, pp. 24-46.

[4] Khodadadi, J. M., Fan, Liwu, and Babaei, H., 2013, "Thermal conductivity enhancement of nanostructure-based colloidal suspensions utilized as phase change materials for thermal energy storage: a review," Renewable and Sustainable Energy Reviews, 24, pp. 418-444.

[5] Khodadadi, J. M. and Hosseinizadeh, S. F., 2007, "Nanoparticle-enhanced phase change materials (NEPCM) with great potential for improved thermal energy storage," International Communications in Heat and Mass Transfer, 34, pp. 534-543.

[6] Rastorguev, Y. L., Bogatov, G. F., and Grigor'ev, B. A., 1974, “Thermal conductivity of higher n-alkanes," Chemistry and Technology of Fuels and Oils, 10, pp. 728-732.

[7] Griggs, E. I., and Yarbrough, D. W., 1978, "Thermal conductivity of solid unbranched alkanes from n-hexadecane to n-eicosane," in Proceedings of the Southeastern Seminar on Thermal Sciences, North Carolina State University, Raleigh, pp. 256-257.

[8] Yarbrough, D. W., and Kuan, C. N., 1981, "The thermal conductivity of solid n-eicosane, n-octadecane, n-heptadecane, n-pentadecane, and n-tetradecane," in Proceeding of the 17th International Thermal Conductivity Conference, pp. 15-19. 
[9] Stryker, P. C., and Sparrow, E. M., 1990, "Application of a spherical thermal conductivity cell to solid n-eicosane paraffin," International Journal of Heat and Mass Transfer, 33, pp. 1781-1793.

[10] Fan, Liwu, 2011, Enhanced thermal conductivity and expedited freezing of nanoparticle suspensions utilized as novel phase change materials, $\mathrm{PhD}$ Thesis, Mechanical Engineering Department, Auburn University, Alabama, USA, http://etd.auburn.edu/etd/bitstream/handle/10415/2707/Dissertation_Fan_0717.pdf?seque nce $=2$.

[11] Nabil, M., 2013, Thermal conductivity of nanostructure-enhanced phase change materials: measurements for solid eicosane-based copper oxide and carbon nanotube colloids and numerical modeling of anomalous measurements near phase transition, M.Sc. Thesis, Mechanical Engineering Department, Auburn University, Alabama, USA, http://etd.auburn.edu/etd/handle/10415/3672.

[12] Fang, X., Fan, L. W., Ding, Q., Wang, X., Yao, X. L., Hou, J. F., Yu, Z. T., Cheng, G. H., Hu, Y. C., and Cen, K. F., 2013, "Increased thermal conductivity of eicosane-based composite phase change materials in the presence of graphene nanoplatelets," Energy \& Fuels, 27, pp. 4041-4047.

[13] Vélez, C., Khayet, M., and de Zárate, J. O., 2015, “Temperature-dependent thermal properties of solid/liquid phase change even-numbered n-alkanes: n-hexadecane, noctadecane and n-eicosane," Applied Energy, 143, pp. 383-394.

[14] Al Ghossein, R. M., 2015, Thermal conductivity enhancement of solid eicosane-based silver nanostructure-enhanced phase change materials for thermal energy storage, M.Sc. Thesis, Mechanical Engineering Department, Auburn University, Alabama, USA. 
[15] Zeng, J. L., Cao, Z., Yang, D. W., Sun, L. X., and Zhang, L, 2010, “Thermal conductivity enhancement of Ag nanowires on an organic phase change material," Journal of Thermal Analysis and Calorimetry, 101, pp. 385-389.

[16] Parameshwaran, R., Jayavel, R., and Kalaiselvam, S., 2013, "Study on thermal properties of organic ester phase-change material embedded with silver nanoparticles," Journal of Thermal Analysis and Calorimetry, 114, pp. 845-858.

[17] Parameshwaran, R., Dhamodharan, P., and Kalaiselvam, S., 2013, "Study on thermal storage properties of hybrid nanocomposite-dibasic ester as phase change material," Thermochimica Acta, 573, pp. 106-120.

[18] Parameshwaran, R., Deepak, K., Saravanan, R., and Kalaiselvam, S., 2014, "Preparation, thermal and rheological properties of hybrid nanocomposite phase change material for thermal energy storage," Applied Energy, 115, pp. 320-330.

[19] Molaba, M. P., Dudić, D., and Luyt, A. S., 2015, "Influence of the presence of mediumsoft paraffin wax on the morphology and properties of iPP/silver nanocomposites," Express Polymer Letters, 9, 901-915.

[20] Nabil, M. and Khodadadi, J. M., 2013, "Experimental determination of temperaturedependent thermal conductivity of solid eicosane-based nanostructure-enhanced phase change materials," International Journal of Heat and Mass Transfer, 67, pp. 301-310.

[21] Freund, M., Csikos, R., Keszthelyi, S. and Mozes, GY., 1982, Paraffin Products: Properties, technologies, applications, ed. GY. Mozes, Elsevier Scientific Publishing Company, Amsterdam-Oxford-New York, Chapters 1 and 3.

[22] Lide, D., 2005, CRC Handbook of Chemistry and Physics, Internet Version 2005, http://www.hbcpnetbase.com, CRC Press, Boca Raton, FL, pp. 12.219-12.220. 
[23] Hossain, M. S., and Mills, G., 2015, Department of Chemistry, Auburn University, Private Communication.

[24] Darvin, J. R., Nabil, M., Uertz, J., and Mills, G., 2016, "Concentrated Ag colloids in dodecane relevant to nanostructure-enhanced PCM," to appear in Chemistry of Materials.

[25] Noggle, J. H., 1989, Physical Chemistry, 2nd ed., Harper Collins Publishers, USA, Chapter 7.

[26] Kolesnikov, S. I. and Syunyaev, Z. I., 1985, "Phase transitions in the melting and

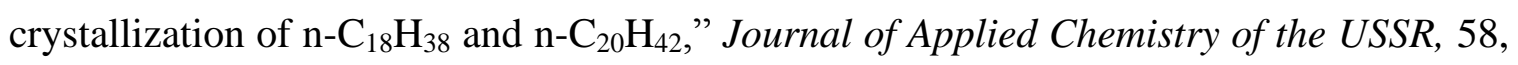
10, pp. 2097-2101.

[27] Nyburg, S. C., and Potworowski, J. A., 1973, "Prediction of unit cells and atomic coordinates for the n-alkanes," Acta Crystallographica Section B: Structural Crystallography and Crystal Chemistry, 29, pp. 347-352.

[28] Müller, A., and Lonsdale, K., 1948, "The low-temperature form of $\mathrm{C}_{18} \mathrm{H}_{38}$," Acta Crystallographica, 1, pp. 129-131.

[29] Broadhurst, M. G., 1962, "An analysis of the solid phase behavior of the normal paraffins," Journal of Research of the National Bureau of Standards Section A: Physics and Chemistry, 66, pp. 241-249.

[30] Piper, S. H., and Malkin, T., 1930, “Crystal structure of normal paraffins," Nature, 126, pp. 278.

[31] Maxwell, J. C., 1881, A Treatise on Electricity and Magnetism, Volume 1, 2nd ed., Clarendon Press, Oxford, UK.

[32] Yaws, C. L., 2009, Transport Properties of Chemicals and Hydrocarbons, William Andrew, Norwich, New York, USA. 
[33] Kline, S. J., and McClintock, F., 1953, "Describing uncertainties in single-sample experiments," Mechanical Engineering, 75, pp. 3-8. 


\section{List of Tables}

Table 1 Thermal conductivity measured data of pure eicosane in the solid state

Table 2 Thermal conductivity measured data of pure eicosane in the liquid state

Table 3 Thermal conductivity measured data of silver-based nanostructure-enhanced phase change materials in the solid state

Table 4 Experimental and theoretical heat of fusion and melting point data of the solid pure eicosane and Ag/eicosane composites, prepared at room temperature, obtained by Differential Scanning Calorimetry (DSC) using the ramping rate of $5{ }^{\circ} \mathrm{C} / \mathrm{min}$ (densities of eicosane and silver used were 840 and $10,500 \mathrm{~kg} / \mathrm{m}^{3}$, respectively) 
Table 1 Thermal conductivity measured data of pure eicosane in the solid state

\begin{tabular}{|c|c|c|c|c|c|c|c|c|}
\hline & $\begin{array}{c}\text { Griggs } \\
\text { and } \\
\text { Yarbrough } \\
\text { [7] (1978) }\end{array}$ & $\begin{array}{c}\text { Yarbrough } \\
\text { and } \\
\text { Kuan [8] } \\
\text { (1981) }\end{array}$ & $\begin{array}{c}\text { Stryker } \\
\text { and } \\
\text { Sparrow } \\
\text { [9] } \\
\text { (1990) }\end{array}$ & $\begin{array}{l}\text { Fan } \\
{[10]} \\
(2011)\end{array}$ & $\begin{array}{c}\text { Nabil } \\
{[11]} \\
(2013)\end{array}$ & $\begin{array}{c}\text { Fang et } \\
\text { al. [12] } \\
\text { (2013) }\end{array}$ & $\begin{array}{l}\text { Velez } \\
\text { et al. } \\
\text { [13] } \\
(2014)\end{array}$ & $\begin{array}{c}A l \\
\text { Ghossein } \\
{[14]} \\
(2015)\end{array}$ \\
\hline Instrument & $S S^{l}$ & $S S$ & $S S$ & $T P S^{2}$ & $T P S$ & $T P S$ & $T H W^{3}$ & TPS \\
\hline $\begin{array}{c}\text { Temperature } \\
\left({ }^{\circ} \mathrm{C}\right)\end{array}$ & $\begin{array}{c}k \\
(W / m K)\end{array}$ & $\begin{array}{c}k \\
(W / m K)\end{array}$ & $\begin{array}{c}k \\
(W / m K)\end{array}$ & $\begin{array}{c}k \\
(W / m K)\end{array}$ & $\begin{array}{c}k \\
(W / m K)\end{array}$ & $\begin{array}{c}k \\
(W / m K)\end{array}$ & $\begin{array}{c}k \\
(W / m K)\end{array}$ & $\begin{array}{c}k \\
(W / m K)\end{array}$ \\
\hline 2 & & 0.413 & & & & & & \\
\hline 6 & & 0.393 & & & & & & \\
\hline 10 & & 0.392 & 0.4229 & & 0.4212 & 0.4137 & 0.438 & 0.4212 \\
\hline 13 & & 0.355 & & & & & & \\
\hline 15 & & 0.344 & 0.4241 & & 0.423 & 0.4031 & 0.425 & 0.4236 \\
\hline 20 & & 0.341 & 0.4235 & 0.4236 & 0.4223 & 0.3956 & 0.388 & 0.4245 \\
\hline 25 & 0.3569 & & 0.4224 & & 0.4241 & 0.3869 & 0.364 & 0.4233 \\
\hline 30 & 0.3375 & & 0.4182 & 0.3866 & 0.4244 & 0.4077 & 0.328 & 0.4241 \\
\hline 31 & & & & & & 0.4382 & & 0.4266 \\
\hline 32 & & & 0.4190 & & 0.4267 & & & 0.4227 \\
\hline 33 & & & & & 0.4229 & 0.7120 & 0.295 & 0.4488 \\
\hline 34 & 0.3104 & & 0.4131 & & 0.4513 & 1.0051 & & 0.4526 \\
\hline 35 & & & & 0.6608 & 0.5503 & 1.407 & & 0.5467 \\
\hline
\end{tabular}

${ }^{1}$ SS denotes the steady-state methods.

${ }^{2}$ TPS denotes the transient plane source technique.

${ }^{3}$ THW denotes the transient hot-wire method. 
Table 2 Thermal conductivity measured data of pure eicosane in the liquid state

\begin{tabular}{|c|c|c|c|}
\hline & $\begin{array}{c}\text { Rastorguev } \\
\text { et al. [6] } \\
\text { (1974) }\end{array}$ & $\begin{array}{c}\text { Fan [10] } \\
(2011)\end{array}$ & $\begin{array}{c}\text { Velez et } \\
\text { al. [13] } \\
(2014)\end{array}$ \\
\hline Instrument & $H F M^{I}$ & $T P S^{2}$ & $T H W^{3}$ \\
\hline $\begin{array}{c}\text { Temperature } \\
\left({ }^{\circ} \mathrm{C}\right)\end{array}$ & $k(W / m K)$ & $\begin{array}{c}k \\
(W / m K)\end{array}$ & $\begin{array}{c}k \\
(W / m K)\end{array}$ \\
\hline 40 & & 0.1485 & 0.1543 \\
\hline 45 & & & 0.1510 \\
\hline 50 & & 0.1473 & 0.1510 \\
\hline 55 & 0.1442 & & 0.1494 \\
\hline 60 & & 0.1432 & 0.1477 \\
\hline 65 & & & 0.1469 \\
\hline 70 & & & 0.1461 \\
\hline 75 & & & 0.1453 \\
\hline 80 & 0.1389 & & \\
\hline 100 & 0.1341 & & \\
\hline 120 & 0.1296 & & \\
\hline 140 & 0.1251 & & \\
\hline 160 & 0.1208 & & \\
\hline 180 & 0.1167 & & \\
\hline 200 & 0.1128 & & \\
\hline
\end{tabular}

${ }^{1}$ HFM denotes the heat filament method.

${ }^{2}$ TPS denotes the transient plane source technique.

${ }^{3}$ THW denotes the transient hot-wire method. 
Table 3 Thermal conductivity measured data of silver-based nanostructure-enhanced phase change materials in the solid state

\begin{tabular}{|c|c|c|c|c|c|c|c|c|c|}
\hline \multicolumn{2}{|c|}{$\begin{array}{c}\text { Zeng et al. }[15] \\
(2010) ; 10-30 \mathrm{~nm} \\
\text { diameter wires with } \\
\text { length of } 5-15 \text { microns }\end{array}$} & \multicolumn{2}{|c|}{$\begin{array}{l}\text { Parameshwaran, } \\
\text { Jayavel and } \\
\text { Kalaiselvam [16] } \\
\text { (2013); 10-18 nm } \\
\text { diameter }\end{array}$} & \multicolumn{2}{|c|}{$\begin{array}{c}\text { Parameshwaran, } \\
\text { Dhamodharan, and } \\
\text { Kalaiselvam [17] } \\
\text { (2013); } 63 \text { nm average } \\
\text { diameter } \\
\end{array}$} & \multicolumn{2}{|c|}{$\begin{array}{c}\text { Parameshwaran, } \\
\text { Deepak, Saravanan and } \\
\text { Kalaiselvam [18] } \\
\text { (2014); } 63 \text { nm average } \\
\text { diameter }\end{array}$} & \multicolumn{2}{|c|}{$\begin{array}{c}\text { Molaba, Dudic and Luyt } \\
\text { [19] } \\
\text { (2015); } 30-50 \mathrm{~nm} \\
\text { diameter }\end{array}$} \\
\hline Instrument & $T P S^{I}$ & Instrument & $L F A^{2}$ & Instrument & $L F A$ & Instrument & $L F A$ & Instrument & $T P S$ \\
\hline $\begin{array}{c}A g N W^{3} \\
w t \%\end{array}$ & $\begin{array}{c}k \\
(W / m K)\end{array}$ & $\begin{array}{c}A g N P^{4} \\
w t \%\end{array}$ & $\begin{array}{c}k \\
(W / m K)\end{array}$ & $\begin{array}{c}\mathrm{AgTiO}_{2} \\
\mathrm{wt} \%\end{array}$ & $\begin{array}{c}k \\
(W / m K)\end{array}$ & $\mathrm{AgTiO}_{2} w t \%$ & $\begin{array}{c}k \\
(W / m K)\end{array}$ & $A g N P w t \%$ & $\begin{array}{c}k^{5} \\
(W / m K)\end{array}$ \\
\hline 0 & 0.319 & 0 & 0.257 & 0 & 0.3633 & 0 & 0.2543 & 0 & $\begin{array}{c}0.2499 \\
(0.2358)\end{array}$ \\
\hline 9.09 & 0.419 & 0.1 & 0.284 & 0.08 & 0.3844 & 0.1 & 0.2830 & 2 & $\begin{array}{c}0.2699 \\
(0.2407)\end{array}$ \\
\hline 23.08 & 0.497 & 0.5 & 0.335 & 0.15 & 0.4071 & 0.5 & 0.3466 & 3 & $\begin{array}{c}0.2881 \\
(0.2391)\end{array}$ \\
\hline 37.58 & 0.606 & 1 & 0.447 & 0.3 & 0.4857 & 0.8 & 0.4214 & 4 & $\begin{array}{c}0.2987 \\
(0.2604)\end{array}$ \\
\hline 46.08 & 0.828 & 2 & 0.596 & 0.7 & 0.6235 & 1 & 0.4913 & 5 & $\begin{array}{c}0.2936 \\
(0.2552)\end{array}$ \\
\hline 62.73 & 1.46 & 5 & 0.765 & 1 & 0.8617 & 1.5 & 0.5379 & - & 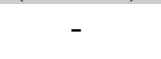 \\
\hline
\end{tabular}

${ }^{1}$ TPS denotes the transient plane source technique.

${ }^{2}$ LFA denotes laser flash analyzer.

${ }^{3} \mathrm{NW}$ denotes nanowires.

${ }^{4} \mathrm{NP}$ denotes nanoparticles.

${ }^{5}$ Values under this column refer to "slowly-cooled" and "quenched-in-ice-water" (within parenthesis) composites. 
Table 4 Experimental and theoretical heat of fusion and melting point data of the solid pure eicosane and Ag/eicosane composites, prepared at room temperature, obtained by Differential Scanning Calorimetry (DSC) using the ramping rate of $5{ }^{\circ} \mathrm{C} / \mathrm{min}$ (densities of solid eicosane and silver used were 840 and $10,500 \mathrm{~kg} / \mathrm{m}^{3}$, respectively)

\begin{tabular}{|c|c|c|c|c|c|}
\hline $\begin{array}{c}A g \\
(w t \%) \\
\left(\text { vol }^{1}\right)\end{array}$ & $\begin{array}{c}\text { Effective } \\
\text { Densities of } \\
\text { PCM } \\
\text { Composites } \\
\left(\mathrm{kg} / \mathrm{m}^{3}\right), \text { Eq. } \\
\text { (5) }\end{array}$ & $\begin{array}{l}\text { Theoretical } \\
\text { Heat of } \\
\text { Fusion } \\
(\mathrm{J} / \mathrm{g}) \\
\text { Eq. (4) }\end{array}$ & $\begin{array}{c}\text { Experimental } \\
\text { Heat of Fusion } \\
(\mathrm{J} / \mathrm{g})\end{array}$ & $\begin{array}{c}\text { Theoretical } \\
\text { Melting } \\
\text { Point }\left({ }^{\circ} \mathrm{C}\right), \\
\text { Eq. }(1) \\
\text { Noggle [25] }\end{array}$ & $\begin{array}{l}\text { Experimental } \\
\text { Melting Point } \\
\quad\left({ }^{\circ} \mathrm{C}\right)\end{array}$ \\
\hline $\begin{array}{l}0 \\
0\end{array}$ & 840 & 247.5 & 241 & 36.4 & 37 \\
\hline $\begin{array}{c}1 \\
0.081\end{array}$ & 847.8 & 245 & 229 & 35.9 & 36.8 \\
\hline $\begin{array}{c}2 \\
0.163\end{array}$ & 855.7 & 242.6 & 208 & 35.66 & 36.5 \\
\hline $\begin{array}{c}3.5 \\
0.289\end{array}$ & 867.9 & 238.8 & 192 & 35.1 & 35.9 \\
\hline $\begin{array}{c}5 \\
0.419\end{array}$ & 880.5 & 235.1 & 177 & 34.54 & 35.5 \\
\hline $\begin{array}{c}6.5 \\
0.553\end{array}$ & 893.4 & 231.4 & 147 & 33.98 & 35.1 \\
\hline $\begin{array}{c}8 \\
0.691\end{array}$ & 906.7 & 227.7 & 134 & 33.42 & 34.5 \\
\hline $\begin{array}{c}10 \\
0.881 \\
\end{array}$ & 925.11 & 222.8 & 78.3 & 32.68 & 33.5 \\
\hline
\end{tabular}

${ }^{1}$ Corresponding values of the volume fractions were determined using equation 3. 


\section{$\underline{\text { List of Figures }}$}

Figure 1 Thermal conductivity values of pure eicosane samples at both liquid (right scale) and solid (left scale) states taken from published papers

Figure 2 Thermal conductivity ratios of different types of silver-based nano-enhanced phase change materials (NePCM) in the solid state as a function of the mass fraction of the silver nanostructures at room temperature

Figure 3 (a) TEM image of the Ag nanoparticles taken from a drop of $10 \mathrm{wt} \%$ sample diluted to $5 \times 10^{-3}$ moles by hexane and dried directly on TEM grid and (b) Histogram showing the distribution of size of silver nanoparticles

Figure 4 Photographs of pure eicosane (removed from the mold), 1 and $10 \mathrm{wt} \%$ of Ag/eicosane composites prepared following the room temperature solidification scheme

Figure 5 DSC-based experimental and theoretical data (Noggle [25]) of the phase change temperature of the pure eicosane and Ag/eicosane composites prepared following the room temperature solidification method (DSC ramping rate of $5^{\circ} \mathrm{C} / \mathrm{min}$ )

Figure 6 DSC curves of the exothermic reactions of pure eicosane and Ag/eicosane samples of 1, 2 and $3.5 \mathrm{wt} \%$ prepared following the room temperature solidification approach along with their respective heat of fusion values (DSC ramping rate of $5^{\circ} \mathrm{C} / \mathrm{min}$ )

Figure 7 DSC curves of the exothermic reactions of 5, 6.5, 8 and $10 \mathrm{wt} \% \mathrm{Ag} /$ eicosane samples prepared following the room temperature solidification method along with their respective heat of fusion values (DSC ramping rate of $5{ }^{\circ} \mathrm{C} / \mathrm{min}$ )

Figure 8 (a) DSC curves of the exothermic and endothermic reactions of pure eicosane of the present study prepared following the room temperature solidification along with (b) an inset of 
the DSC curve from Kolesnikov and Syunyaev [26] (DSC ramping rate of $1{ }^{\circ} \mathrm{C} / \mathrm{min}$ ) and (c) schematic diagram of transition from triclinic to hexagonal structure

Figure 9 XRD patterns of pure eicosane, 1 and 10 wt $\%$ Ag/eicosane NePCM composites prepared following the room temperature solidification route, along with an inset of the XRD pattern of silver nanoparticles as prepared by Hossain and Mills [23]

Figure 10 Thermal conductivity of the solid pure eicosane and Ag/eicosane samples prepared following the ice-water bath solidification route, excluding data close to the respective melting point of each NePCM; Reported values are the average of three measurements (maximum standard deviation of $1.3 \%$ )

Figure 11 Comparison of the thermal conductivity of the $10 \mathrm{wt} \%$ Ag/eicosane samples prepared using three different solidification schemes (the stated melting temperature corresponds to the sample prepared following the room temperature route)

Figure 12 Thermal conductivity of the solid pure eicosane and Ag/eicosane samples prepared following the oven solidification route, excluding data close to the respective melting point of each NePCM; Reported values are average of three measurements (maximum standard deviation of $1.3 \%$ )

Figure 13 Thermal conductivity of the solid pure eicosane and Ag/eicosane samples prepared following the ambient temperature solidification route, excluding data close to the respective melting point of each NePCM; Reported values are average of three measurements (maximum standard deviation of $1.4 \%$ )

Figure 14 Relative thermal conductivity of the Ag/eicosane NePCM samples obtained following the room temperature solidification method along with the predictions of Maxwell's equation [31] 
Figure 15 Comparison of the figure of merit among present study ( $\mathrm{Ag}$ nanofillers), $\mathrm{Ag}$ nanoparticles of Molaba et al. [19] and $\mathrm{CuO}$ nanoadditives of Nabil [11] for NePCM composites prepared following the room temperature solidification route along with the limit of the Maxwell's model [31] 


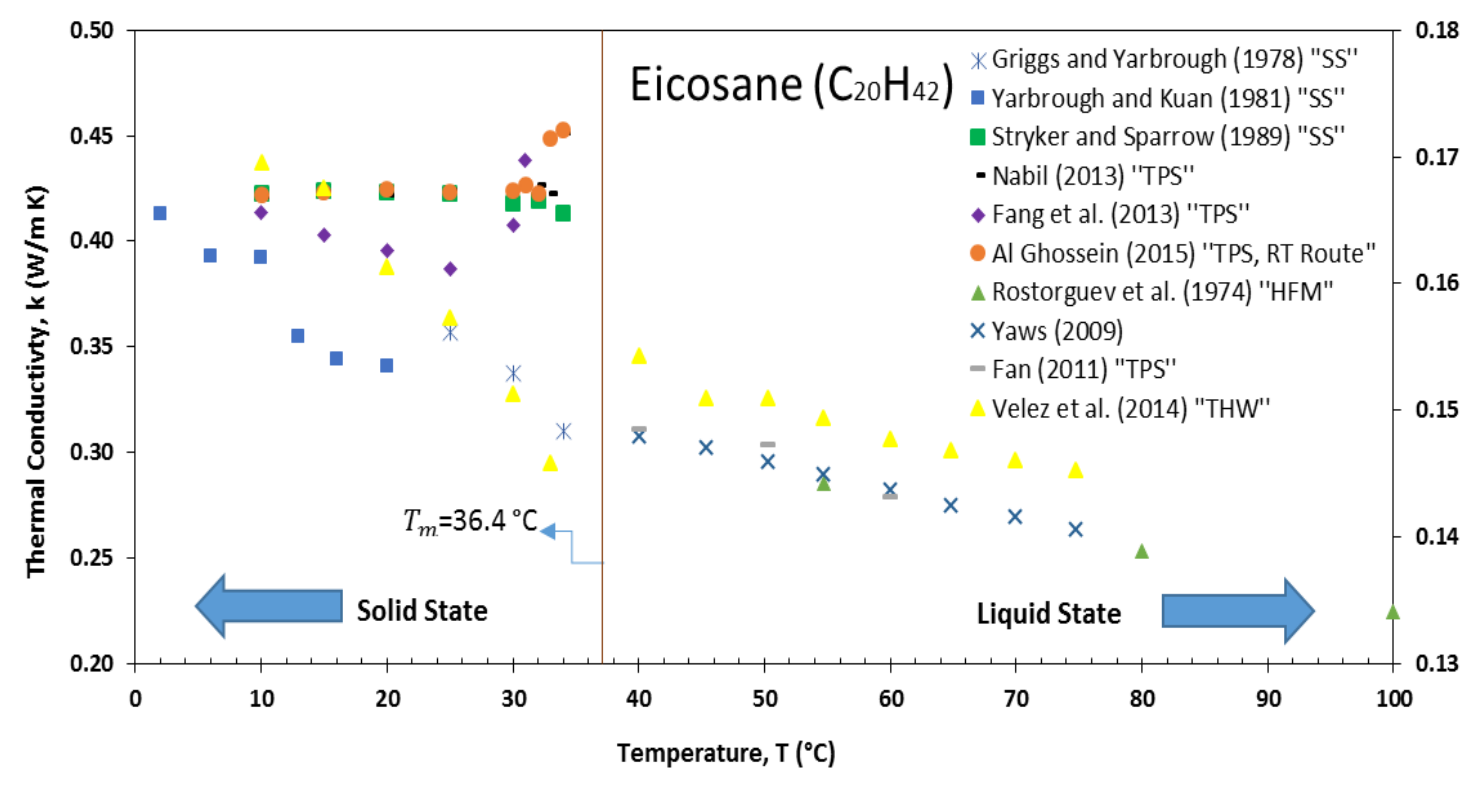

Figure 1 Thermal conductivity values of pure eicosane samples at both liquid (right scale) and solid (left scale) states taken from published papers 


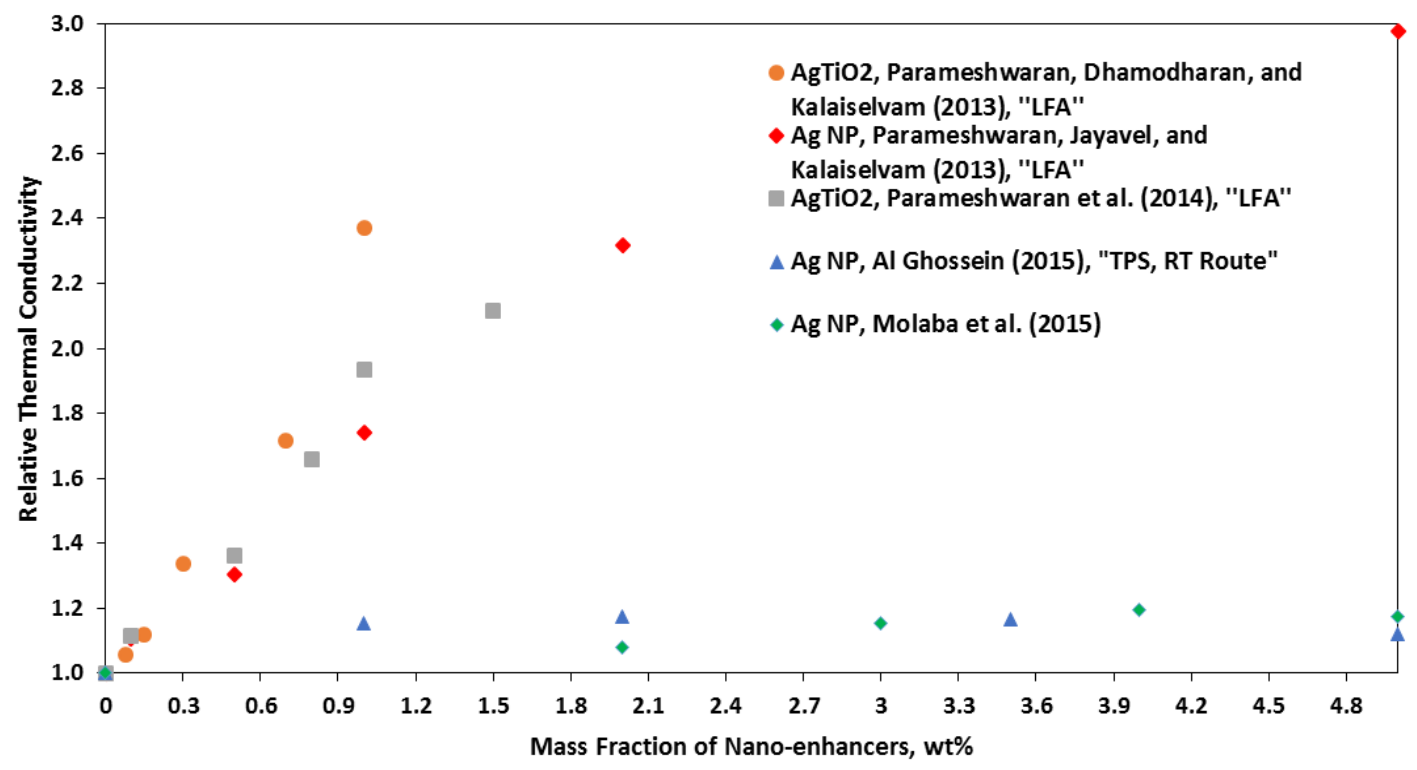

Figure 2 Thermal conductivity ratios of different types of silver-based nano-enhanced phase change materials (NePCM) in the solid state as a function of the mass fraction of the silver nanostructures at room temperature 

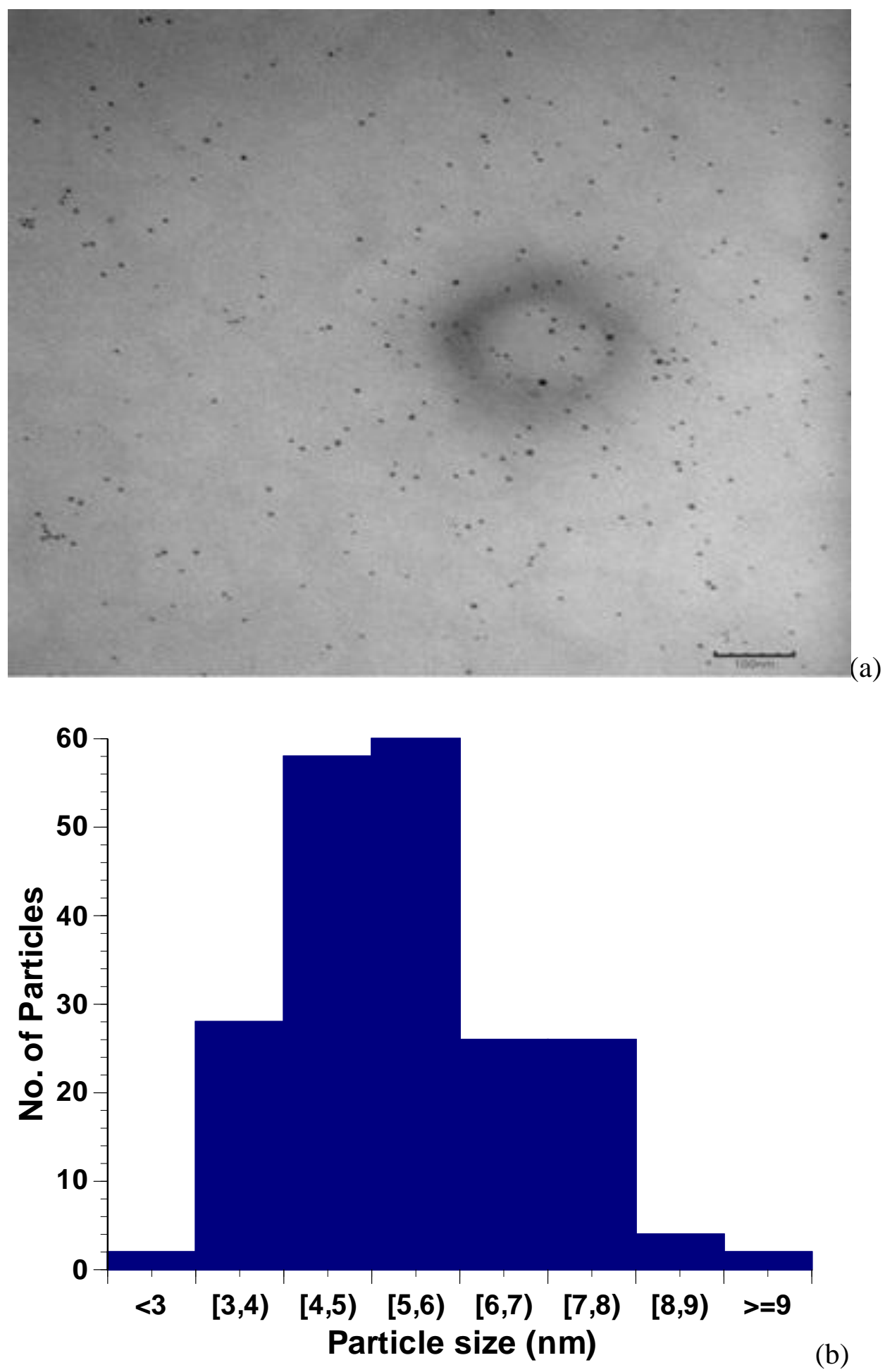

Figure 3 (a) TEM image of the Ag nanoparticles taken from a drop of $10 \mathrm{wt} \%$ sample diluted to $5 \times 10^{-3}$ moles by hexane and dried directly on TEM grid and (b) Histogram showing the distribution of size of silver nanoparticles 


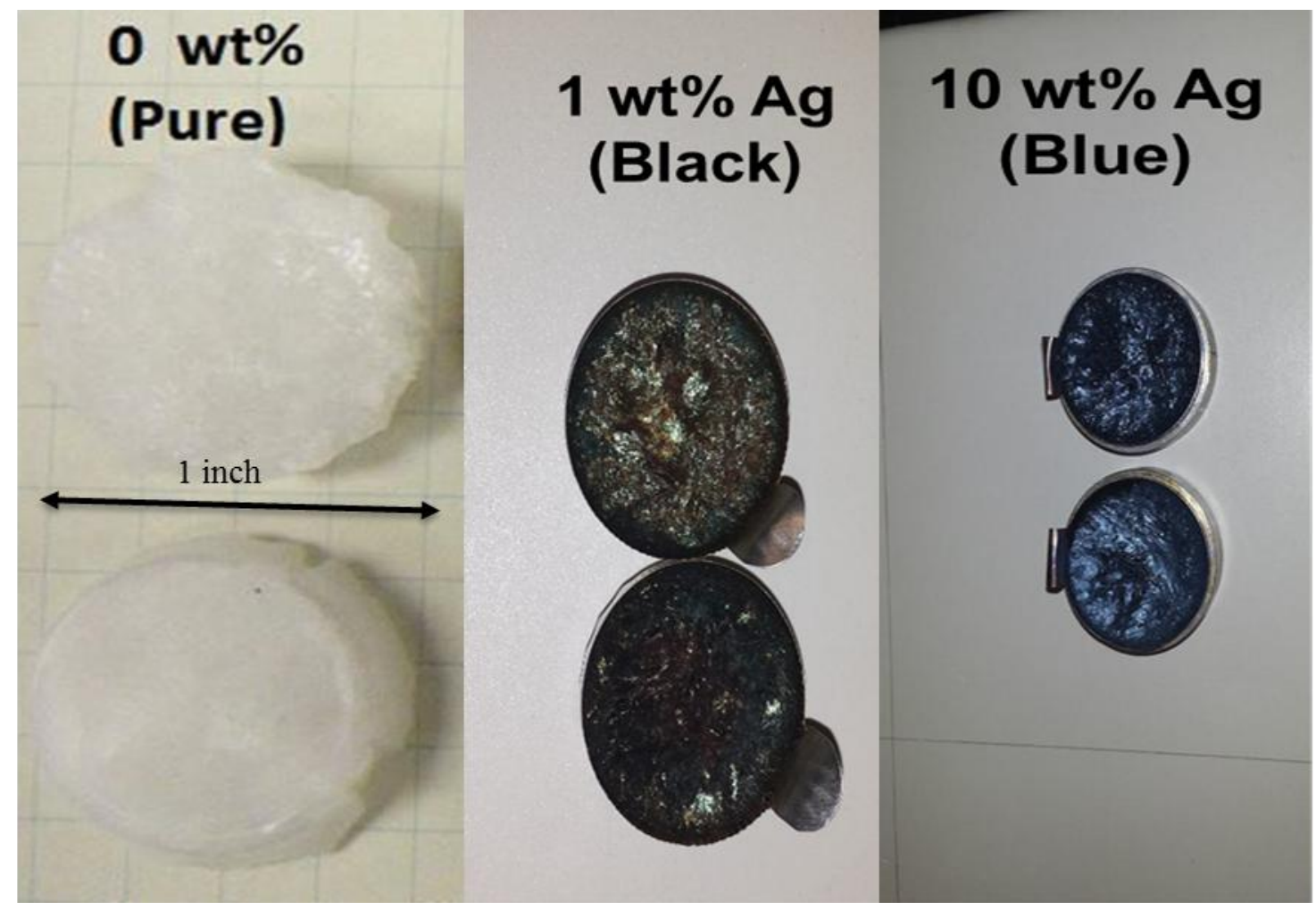

Figure 4 Photographs of pure eicosane (removed from the mold), 1 and $10 \mathrm{wt} \%$ of Ag/eicosane composites prepared following the room temperature solidification scheme 


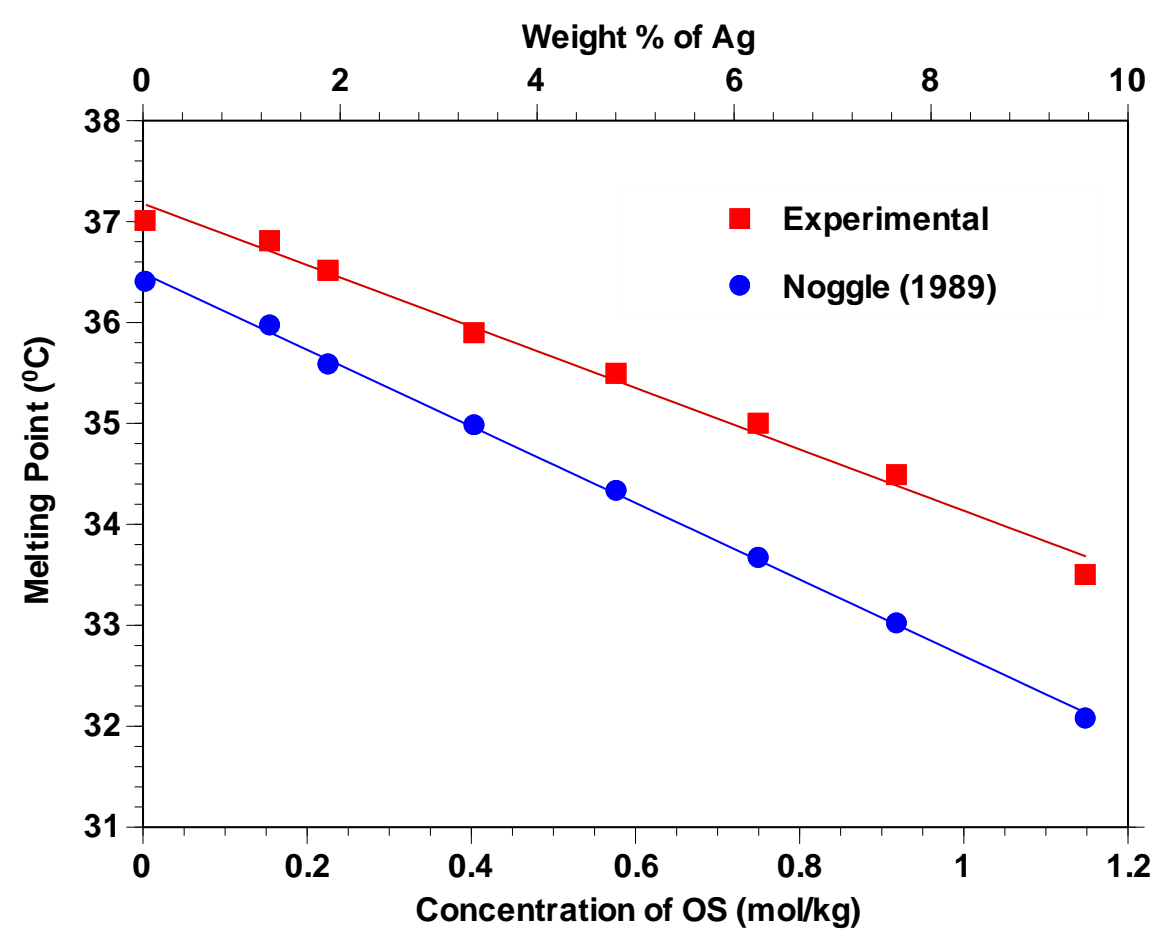

Figure 5 DSC-based experimental and theoretical data (Noggle [25]) of the phase change temperature of the pure eicosane and Ag/eicosane composites prepared following the room temperature solidification method (DSC ramping rate of $5^{\circ} \mathrm{C} / \mathrm{min}$ ) 


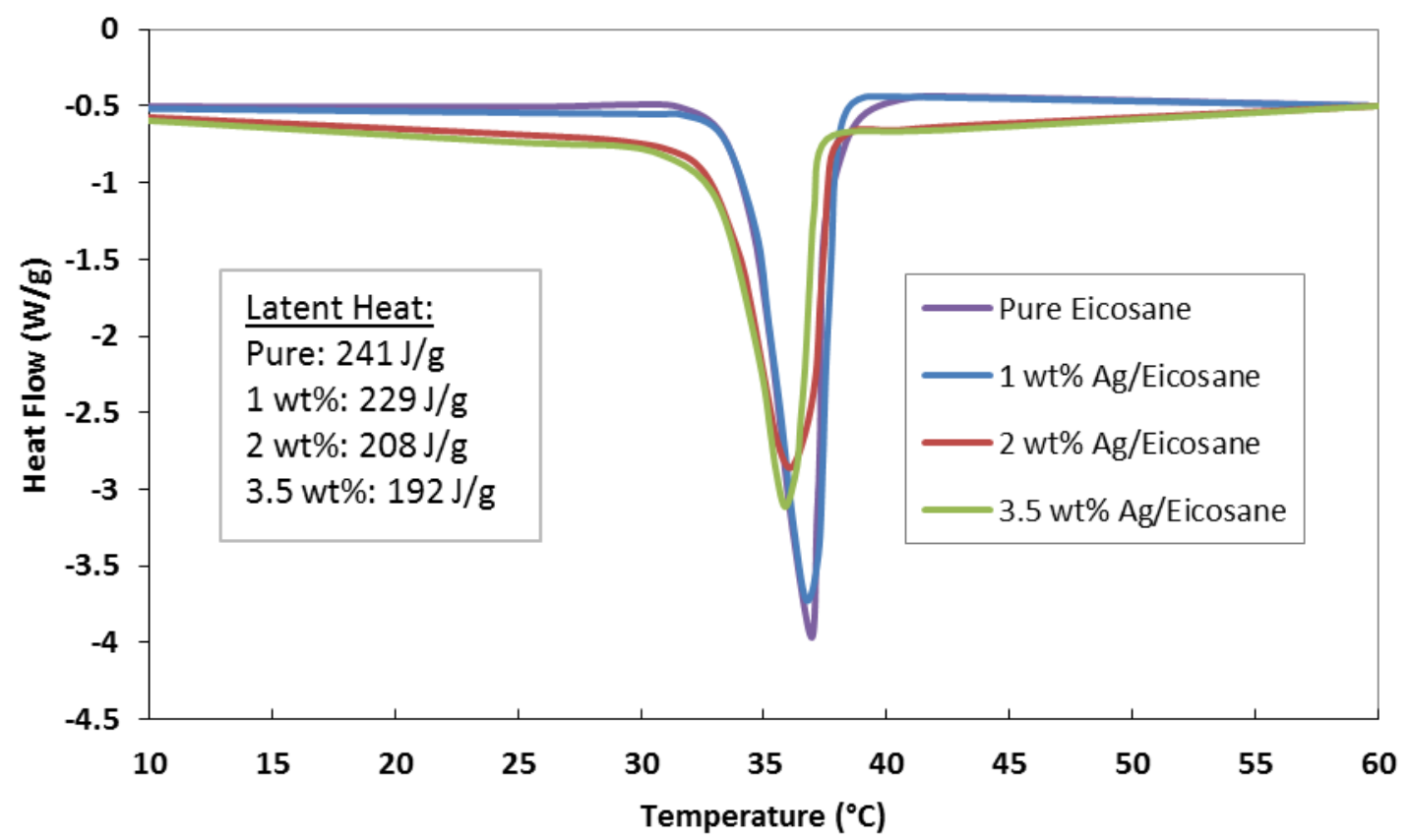

Figure 6 DSC curves of the exothermic reactions of pure eicosane and Ag/eicosane samples of 1,2 and $3.5 \mathrm{wt} \%$ prepared following the room temperature solidification approach along with their respective heat of fusion values (DSC ramping rate of $5{ }^{\circ} \mathrm{C} / \mathrm{min}$ ) 


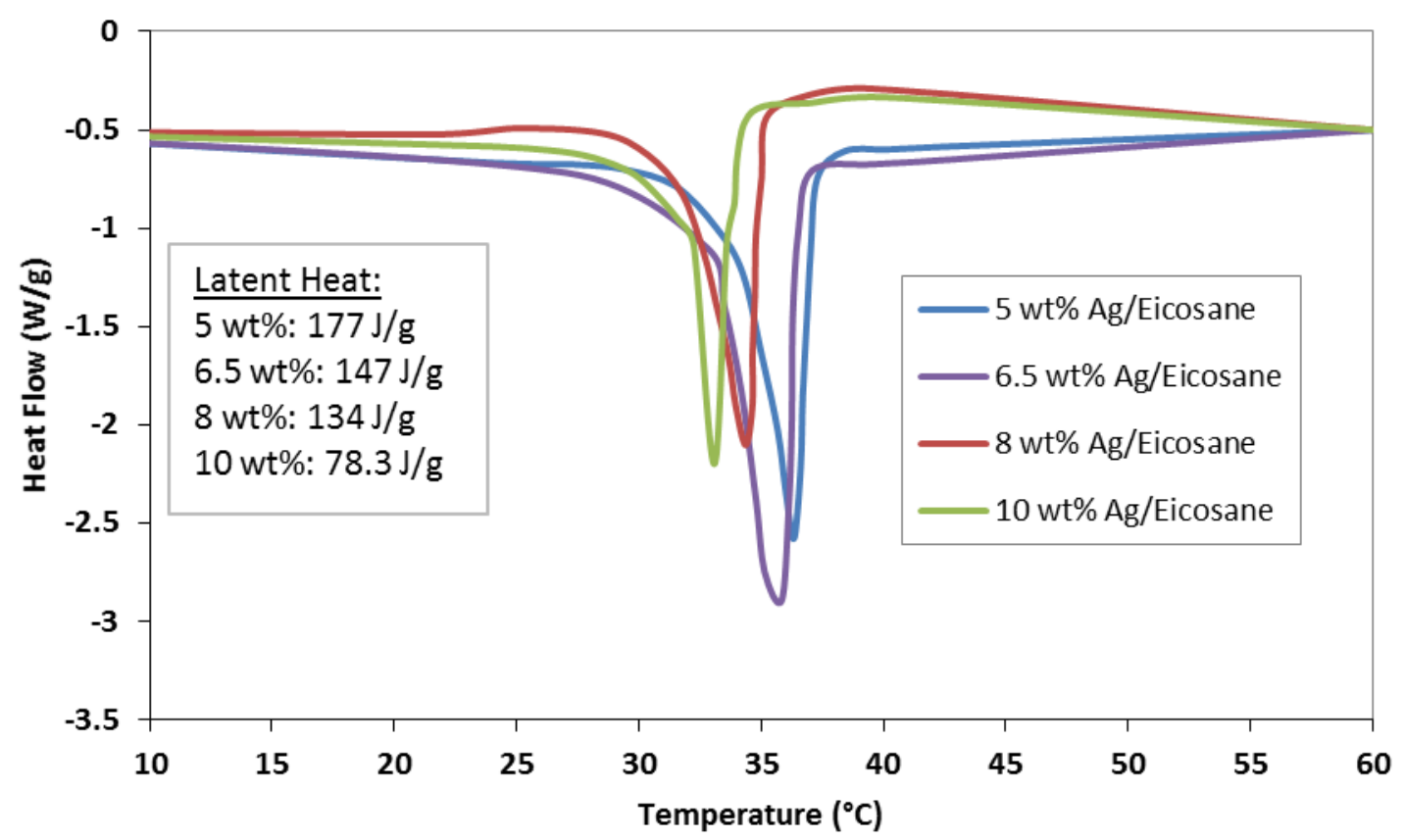

Figure 7 DSC curves of the exothermic reactions of 5, 6.5, 8 and $10 \mathrm{wt} \% \mathrm{Ag} / \mathrm{eicosane}$ samples prepared following the room temperature solidification method along with their respective heat of fusion values (DSC ramping rate of $5{ }^{\circ} \mathrm{C} / \mathrm{min}$ ) 
(a)

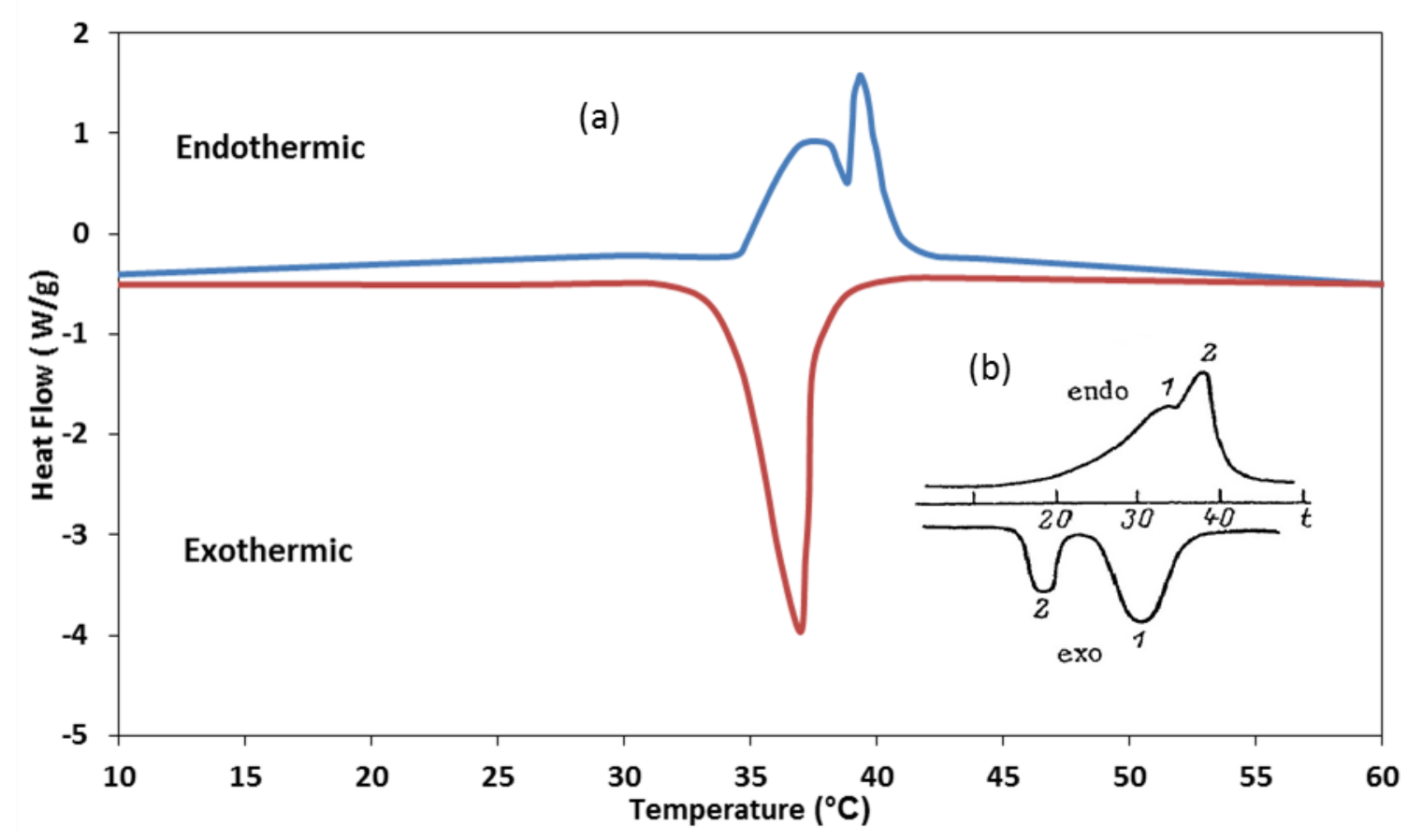

(c)

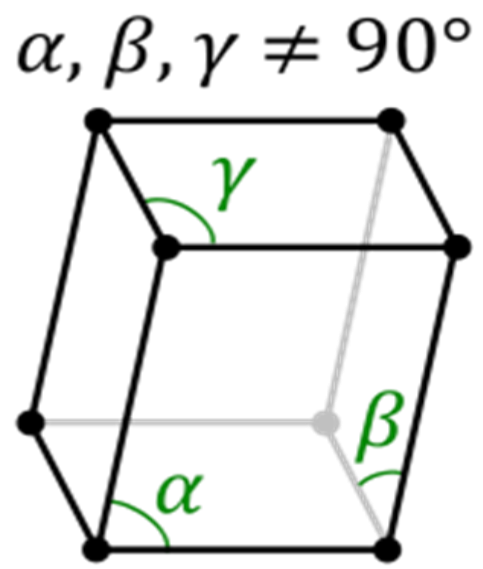

Triclinic Structure

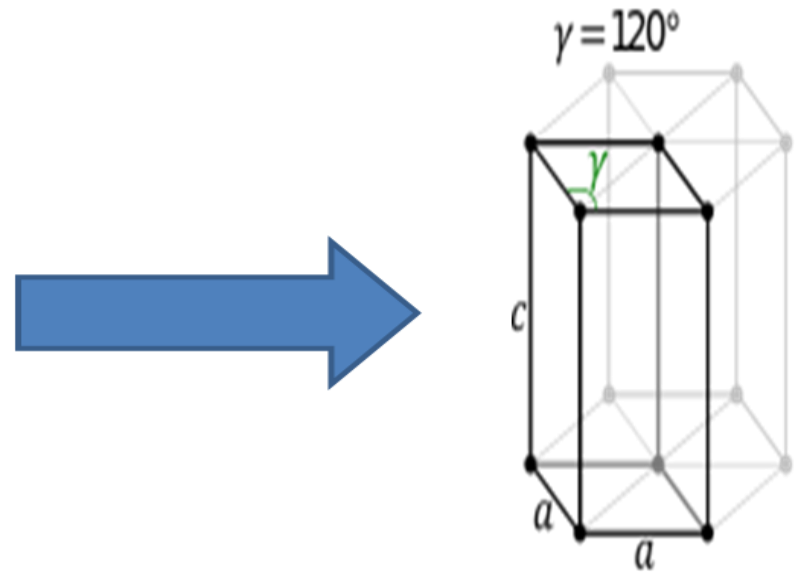

Hexagonal Structure

Figure 8 (a) DSC curves of the exothermic and endothermic reactions of pure eicosane of the present study prepared following the room temperature solidification along with (b) an inset of the DSC curve from Kolesnikov and Syunyaev [26] (DSC ramping rate of $1{ }^{\circ} \mathrm{C} / \mathrm{min}$ ) and (c) schematic diagram of transition from triclinic to hexagonal structure 


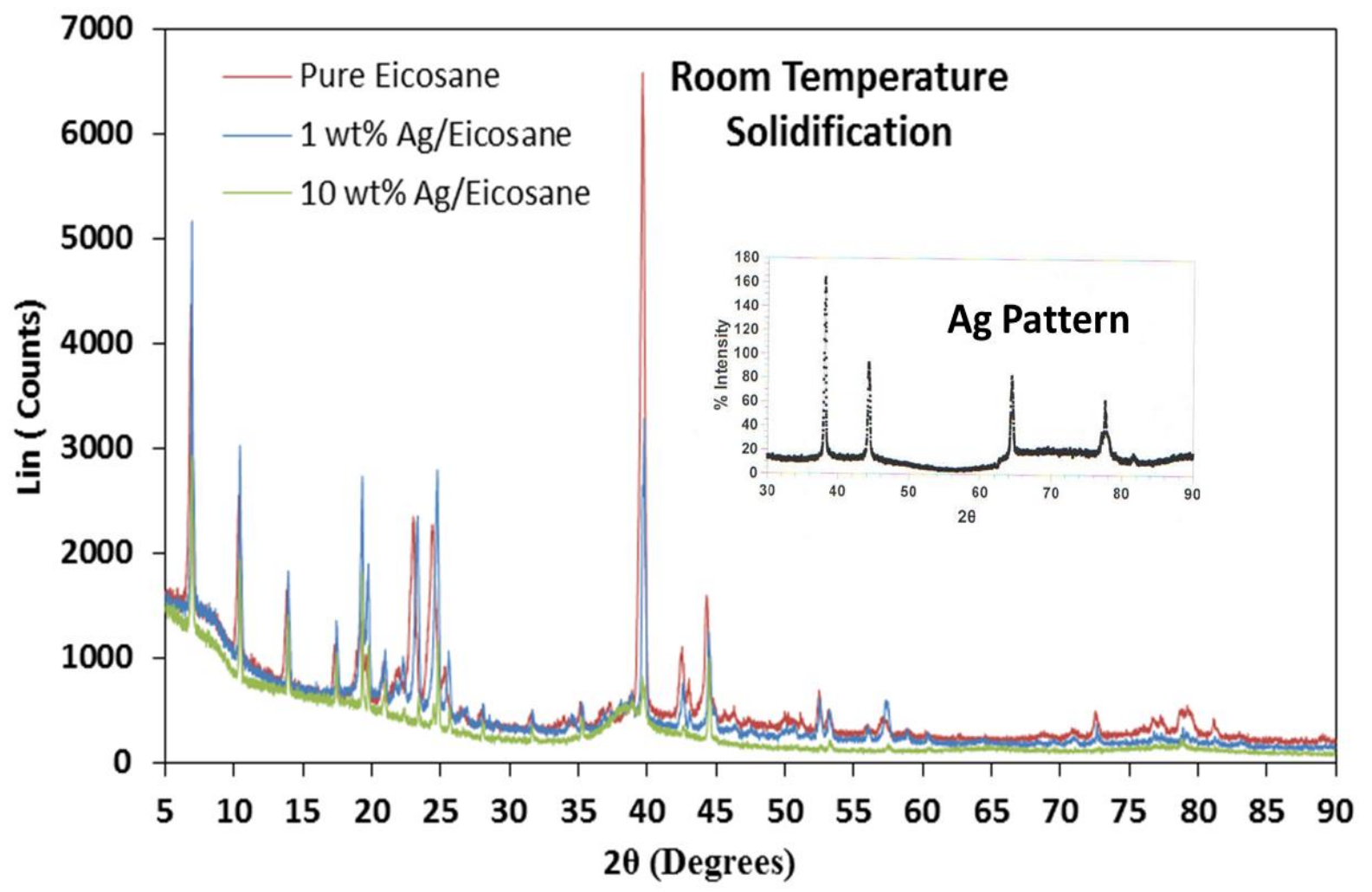

Figure 9 XRD patterns of pure eicosane, 1 and 10 wt $\%$ Ag/eicosane NePCM composites prepared following the room temperature solidification route, along with an inset of the XRD pattern of silver nanoparticles as prepared by Hossain and Mills [23] 


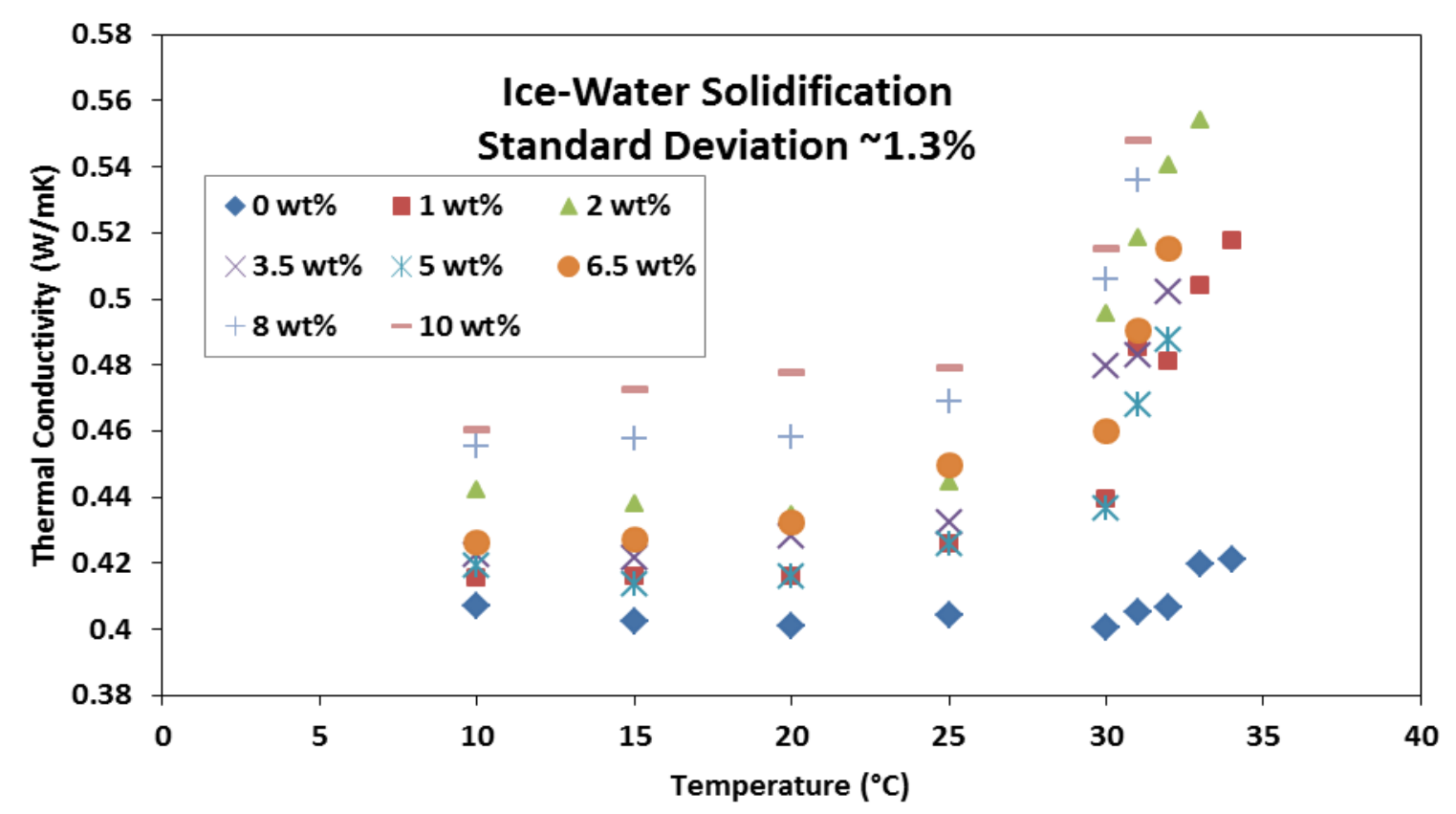

Figure 10 Thermal conductivity of the solid pure eicosane and Ag/eicosane samples prepared following the ice-water bath solidification route, excluding data close to the respective melting point of each NePCM; Reported values are the average of three measurements (maximum standard deviation of $1.3 \%)$ 


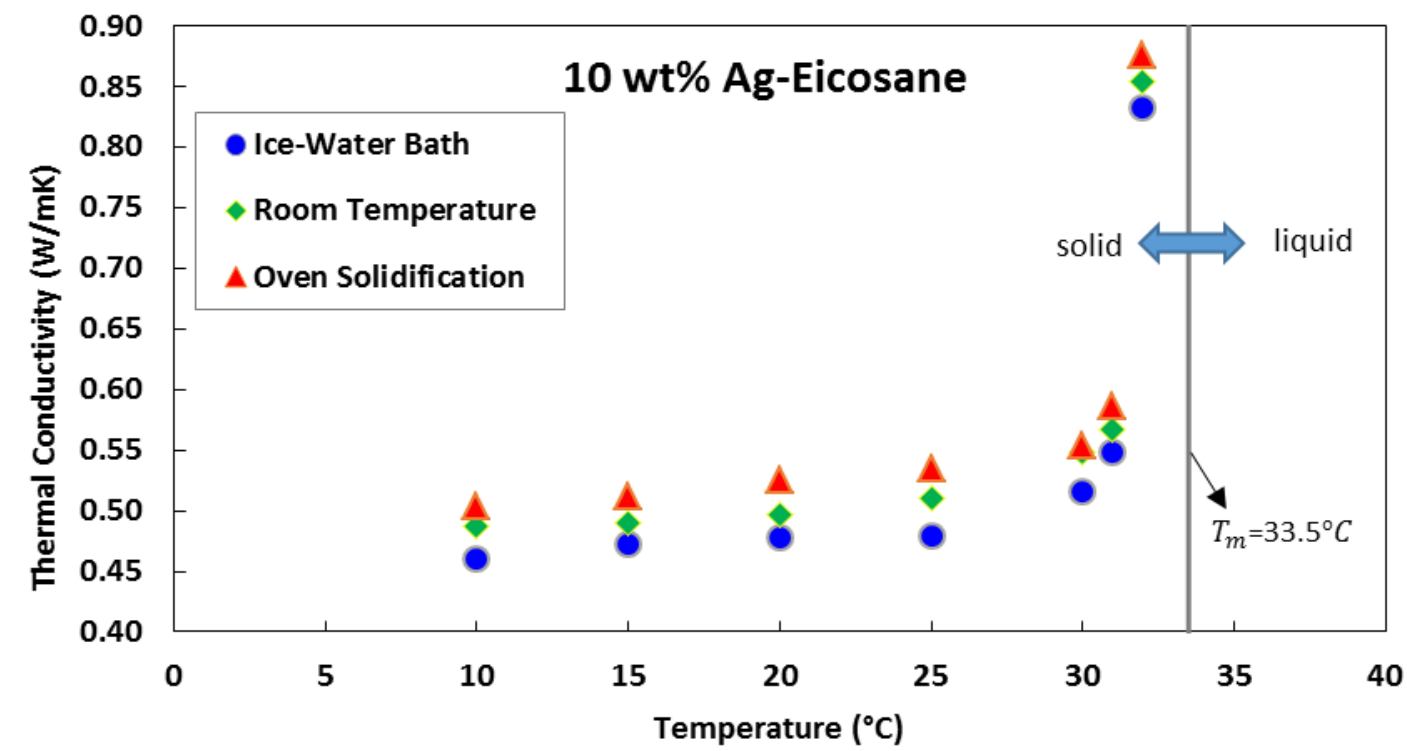

Figure 11 Comparison of the thermal conductivity of the $10 \mathrm{wt} \% \mathrm{Ag} / \mathrm{eicosane}$ samples prepared using three different solidification schemes (the stated melting temperature corresponds to the sample prepared following the room temperature route) 


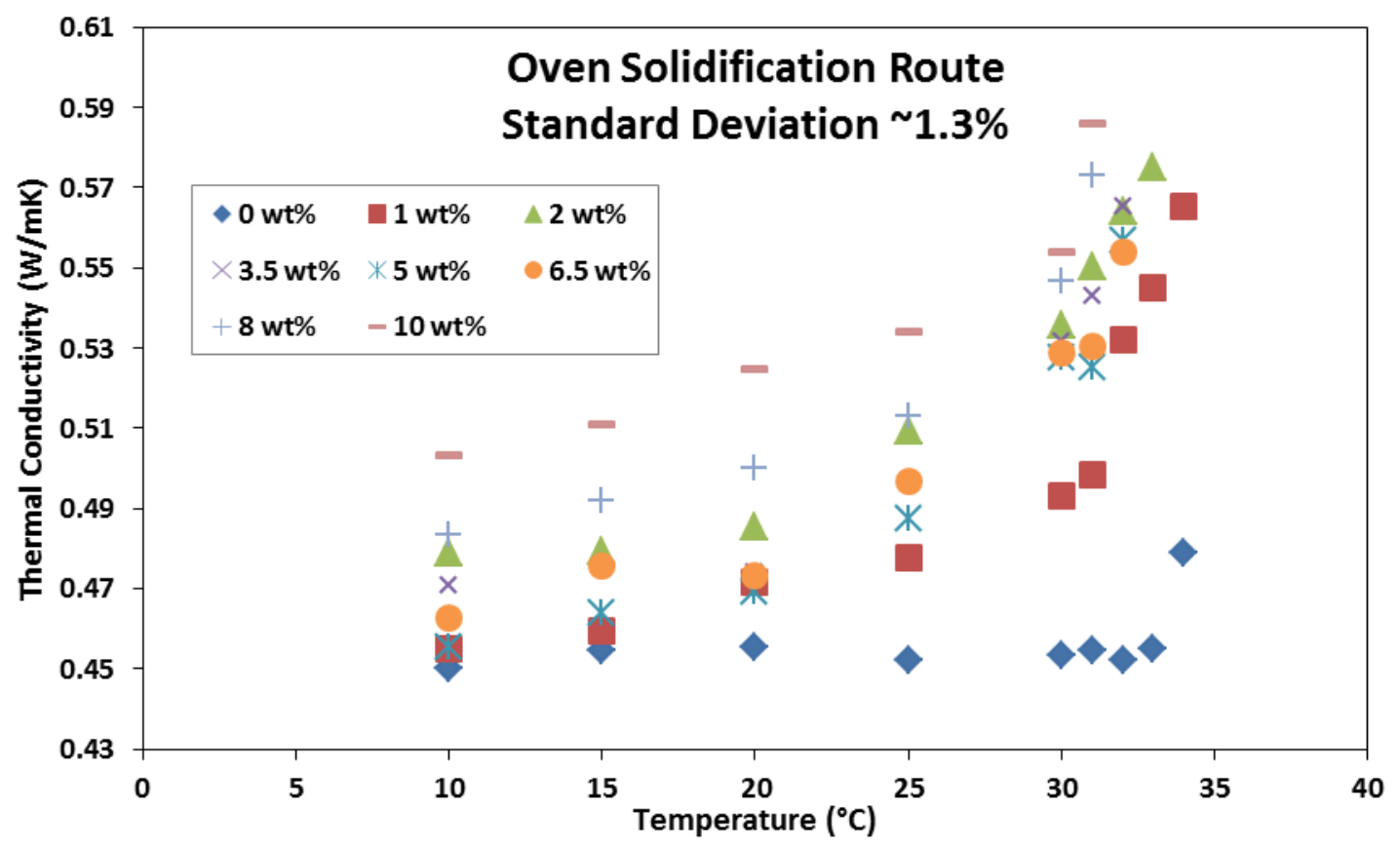

Figure 12 Thermal conductivity of the solid pure eicosane and Ag/eicosane samples prepared following the oven solidification route, excluding data close to the respective melting point of each NePCM; Reported values are average of three measurements (maximum standard deviation of $1.3 \%)$ 


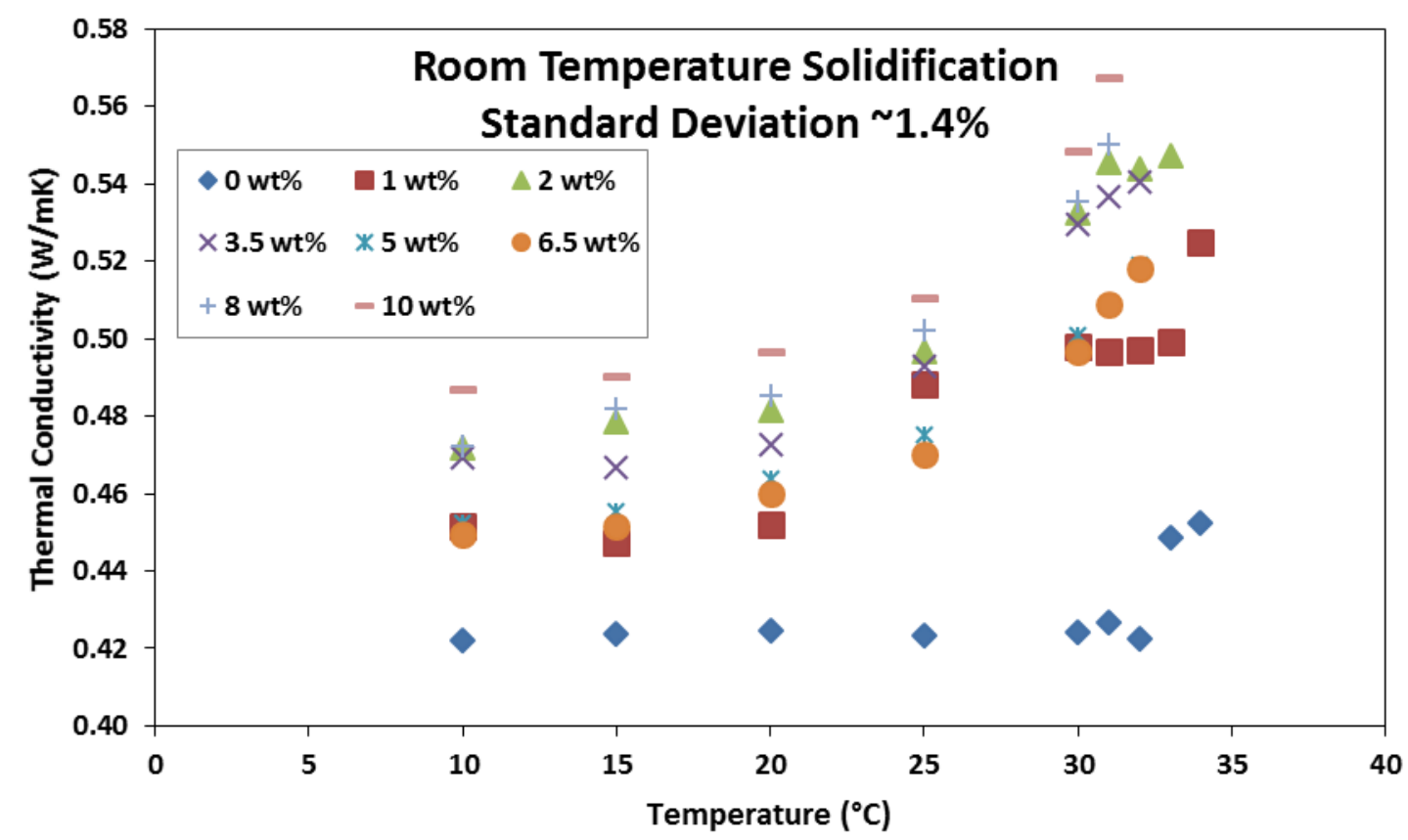

Figure 13 Thermal conductivity of the solid pure eicosane and Ag/eicosane samples prepared following the ambient temperature solidification route, excluding data close to the respective melting point of each NePCM; Reported values are average of three measurements (maximum standard deviation of $1.4 \%$ ) 


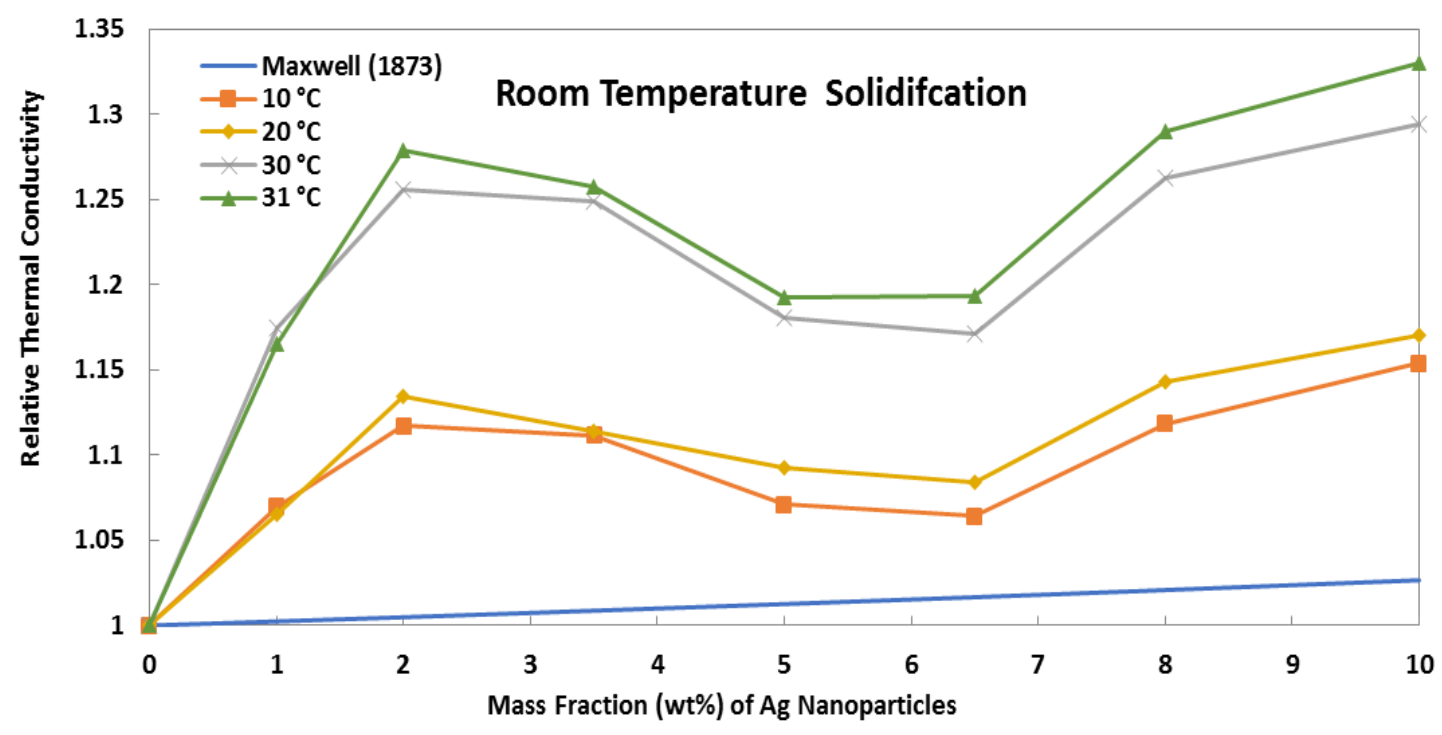

Figure 14 Relative thermal conductivity of the Ag/eicosane NePCM samples obtained following the room temperature solidification method along with the predictions of Maxwell's equation [31] 


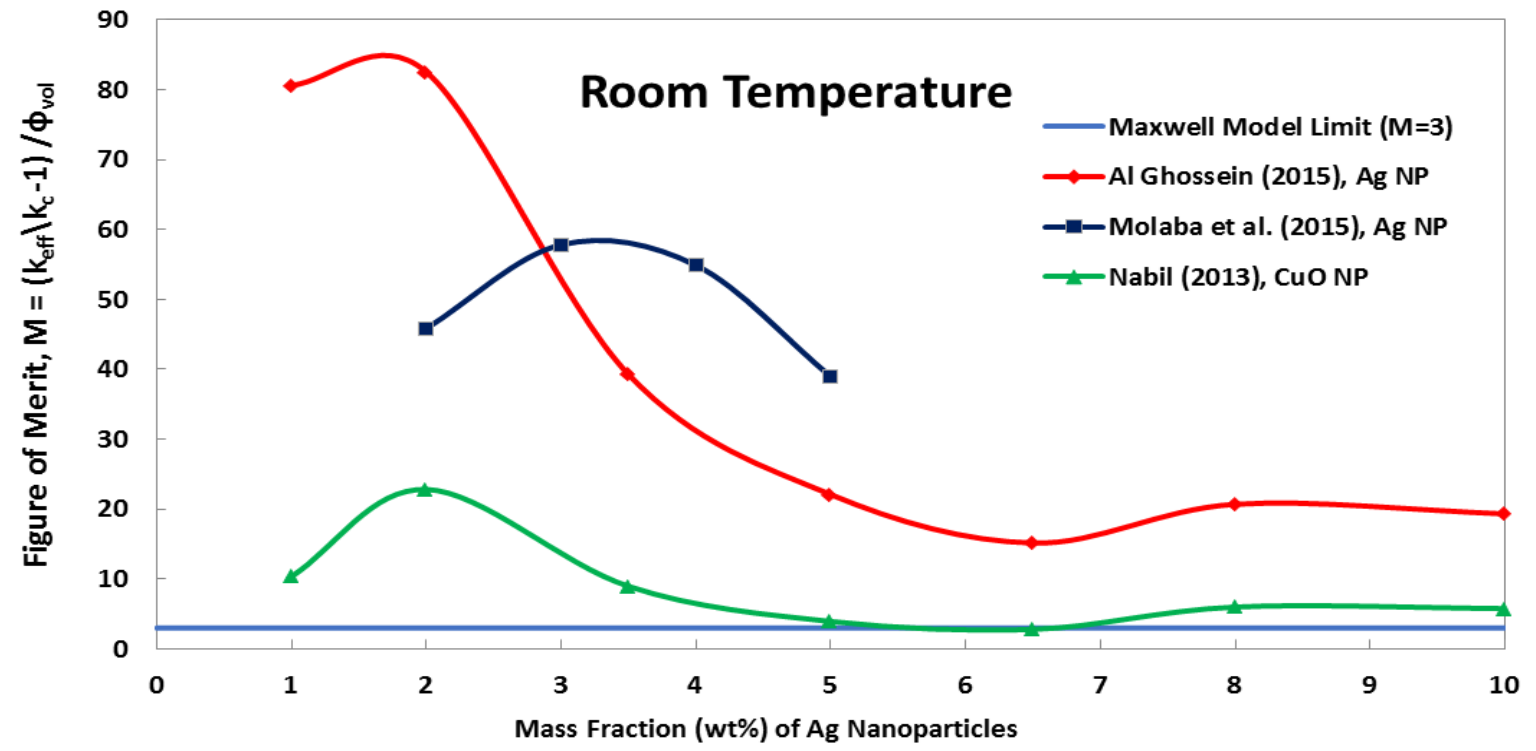

Figure 15 Comparison of the figure of merit among present study (Ag nanofillers), $\mathrm{Ag}$ nanoparticles of Molaba et al. [19] and $\mathrm{CuO}$ nanoadditives of Nabil [11] for NePCM composites prepared following the room temperature solidification route along with the limit of the Maxwell's model [31] 